\title{
Simplified two-dimensional modelling to constrain the deep groundwater contribution in a complex mineral water mixing area, Riardo Plain, southern Italy
}

\author{
Stefano Viaroli ${ }^{1}$ (D) Francesca Lotti $^{2} \cdot$ Lucia Mastrorillo $^{1} \cdot$ Vittorio Paolucci $^{3} \cdot$ Roberto Mazza $^{1}$
}

Received: 29 May 2018 / Accepted: 2 December 2018 / Published online: 9 January 2019

(C) The Author(s) 2019

\begin{abstract}
Complex hydrogeological systems require detailed knowledge of aquifer dynamics to ensure appropriate and sustainable management of the groundwater resource. The Riardo Plain aquifer, southern Italy, is a strategic resource for conjunctive uses; nevertheless, the conceptual model still suffers some uncertainties due to the presence of a deep lateral inflow through the carbonate basement. Therefore, the realisation of a 3D numerical model at catchment scale needs preliminary tests to constrain the possible additional inflow rate, which is at the moment only estimated through the results of the groundwater budget calculation. A 2D section of the mixing area was modelled using FEFLOW in order to test the hypothesis of a combined recharge. Seven versions of the same model were calibrated over an increasing number of adjustable parameters according to their sensitivity. The most efficient model version was identified according to the calculated information criteria and the sum of squared-weighted residuals. In the second phase of the work, nine model scenarios characterised by different deep inflow rates were calibrated and validated according to the same procedure of the first model, in order to identify the range of possible acceptable solutions. The most likely deep inflow rate is $34 \pm 4 \%$ of the total recharge, corresponding to an estimated deep inflow of $415 \pm 50 \mathrm{~L} / \mathrm{s}$ in the Riardo Plain aquifer through the carbonate basement. This methodological approach will be the basis of following numerical 3D numerical models of the Riardo Plain and can be a valuable tool in conceptualising similar mineral water areas.
\end{abstract}

Keywords Numerical modelling $\cdot$ Mineral aquifer $\cdot$ FEFLOW $\cdot$ Parsimonious models $\cdot$ Italy

\section{Introduction}

Numerical modelling of aquifers at catchment scale is a fundamental tool for the management of all groundwater resources, especially in strategic aquifers exploited for conjunctive purposes. In addition, numerical modelling is a powerful tool to test conceptual models in which some budget terms cannot be

Electronic supplementary material The online version of this article (https://doi.org/10.1007/s10040-018-1910-3) contains supplementary material, which is available to authorized users.

Stefano Viaroli

stefano.viaroli@uniroma3.it

1 Department of Sciences, Roma Tre University, Largo S. Leonardo Murialdo 1, 00146 Roma, Italy

2 Kataclima s.r.l., Via Cassia 92, 01019 Vetralla, VT, Italy

3 Ferrarelle S.p.A, Contrada Ferrarelle, 81053 Riardo, CE, Italy easily estimated or directly measured as in the case of overlapping aquifers, where the possible range of the contribution of deep aquifers in vertical mixing areas can be only estimated (Baiocchi et al. 2013; Maréchal et al. 2013). The numerical models must be supported by reliable hydrogeological conceptual models (Poeter and Anderson 2005; Singh 2014; Zhou and Herath 2017) in order to define the geometry and hydraulic properties of the aquifer layers and the boundary conditions, which influence the simulated system.

The implementation of a regional three-dimensional (3D) numerical model usually suffers many uncertainties depending on the model scale, geometry of the aquifer and reliability of the applied boundary conditions (Bredehoeft 2005; Hill and Tiedeman 2007; Renz et al. 2009; Sepúlveda and Doherty 2015; Giacopetti et al. 2016; Andrés et al. 2017; Lancia et al. 2018). In addition, the calibrated solution is nonunique, as well as dependent on the quantity and quality of observation data and accuracy during field data collection (Poeter and Anderson 2005; Singh et al. 2010). 
Many approaches (Hill 2006; Foglia et al. 2007; Singh et al. 2010; Ye et al. 2010) have been proposed to reduce the uncertainty of a model, using simplifications of the structure and/or statistical methods to quantify the uncertainty when its irreducible limit is reached.

Some authors have reduced the amount of information required through the building of two-dimensional (2D) models, where the absence of the third dimension limits the number of adjustable parameters (Sena and Molinero 2009; Pola et al. 2015; Lancia et al. 2018). In fact, 2D numerical investigations can be performed isolating the salient hydrogeological properties, to explain specific dynamics, which cannot be understood otherwise, due to the high number of unknowns at regional scale.

One of the present approaches makes use of parsimonious models (Carrera and Neuman 1986a, b, c; Massmann et al. 2006; Hill and Tiedeman 2007). Such an approach requires a limited number of parameters to be estimated, where the ideal number is supported by the content of information present in the data. Parsimonious models rely on this limit, since manual regularisation of parameters is applied (geometry of the parameters homogeneous zones is arbitrarily defined manually according to the conceptual model). In this case, as the number of parameters increases, the dataset content of information becomes insufficient to adjust all of them and uncertainty increases consequently. To overcome this limit, highly parametrised methods have been developed (Doherty 2010; Anderson et al. 2015) that are able to better accommodate the salient complexity of reality; the uniqueness of the solution in this case is achieved through mathematical regularisation (i.e., Tikhonov regularisation in PEST). Unlike manual regularisation that seeks uniqueness through inverse problem reduction, with Tikhonov regularisation prior information is added about the parameter field (an additional "parameter observations" dataset including hydraulic test results and other expert knowledge information), so that even ill-posed inverse models can be numerically solved (Doherty 2015).

In the case of the parsimonious approach, the model performances can be evaluated through the information criteria (Engelhardt et al. 2014; Giacopetti et al. 2016), which provide information about the quality of the model estimation, considering both the goodness of the calibration and the complexity of the model.

Riardo Plain aquifer is a strategic drinking water resource for more than 100,000 people, the water storage for $60 \mathrm{~km}^{2}$ of irrigated land, and the source of a mineral-water-bottling plant. The hydrogeological framework of Riardo Plain has been studied since the 1990s by several research teams but its conceptual model still suffers some uncertainties due to the complexity of the aquifer dynamics. Indeed, two aquifers can be identified in the study area: a multilayered volcanic aquifer and a deep confined carbonate aquifer locally mixing with the above volcanic aquifer. The groundwater budget calculation suggested the presence of an additional source of recharge deriving from the lateral inflow through the carbonate ridges surrounding the plain, driven by the sedimentary basement under the volcanic deposits and locally up-flowing in the mineral water mixing area. The recognised complexity of the Riardo Plain hydrogeological setting can be a challenge to test a numerical modelling approach for the validation of the conceptual model and then the management of a complex aquifer, exploited for conjunctive purposes.

With the present level of knowledge, the 3D numerical model of the entire Riardo Plain aquifer suffers due to the high number of unknown parameters, especially a validated additional deep recharge, and due to the clustered distribution of the observations. The first step is, therefore, the validation of the last conceptual model elaborated, focusing on the reliability of the presence of a deep inflow and providing the most efficient range of possible flow rate solutions.

In this study, a simplified approach on a $2 \mathrm{D}$ sub-model using information criteria constraints was applied. Inapplicability of complex 3D hydrological models due to scarce data motivated the need for the simplified 2D modelling approach in an attempt to constrain the results to the available data, isolating the most relevant system processes. The investigated portion of the aquifer is in close proximity to the mineral-water-mixing area, where the volcanic and the carbonate aquifers are still unmixed, and could be separately monitored.

The proposed combined approach has allowed a preliminary $2 \mathrm{D}$ evaluation of the additional deep recharge of the aquifer, particularly useful in following thermal and mineralaquifer-3D-numerical simulation, being the deep resource typically with higher economic relevance, but also harder to directly quantify. Indeed, a 3D aquifer model can be affected by high uncertainties in such hydrogeological frameworks, typically concerning flow rate and up flow localisation. The preimplementation of a 2D model of the mixing area could provide insight on the system unknowns.

\section{Geological and hydrogeological framework}

The study area corresponds to the eastern sector of the Roccamonfina Volcano and to the Riardo Plain, located in the northern part of Campania Region, central-southern Italy (Fig. 1). The investigated area lies between the peri-Tyrrenian sector and the Apennine Orogen (Locardi 1988), characterised by the contact between the Plio-Quaternary volcanic sequences and the Mesozoic to Cenozoic sedimentary basement (Peccerillo 2005).

The basement corresponds to the Meso-Cenozoic Apennine carbonate sequences, highly deformed since the Miocene during the orogenetic phase and later during the Plio-Pleistocene distensive tectonic activity, which 


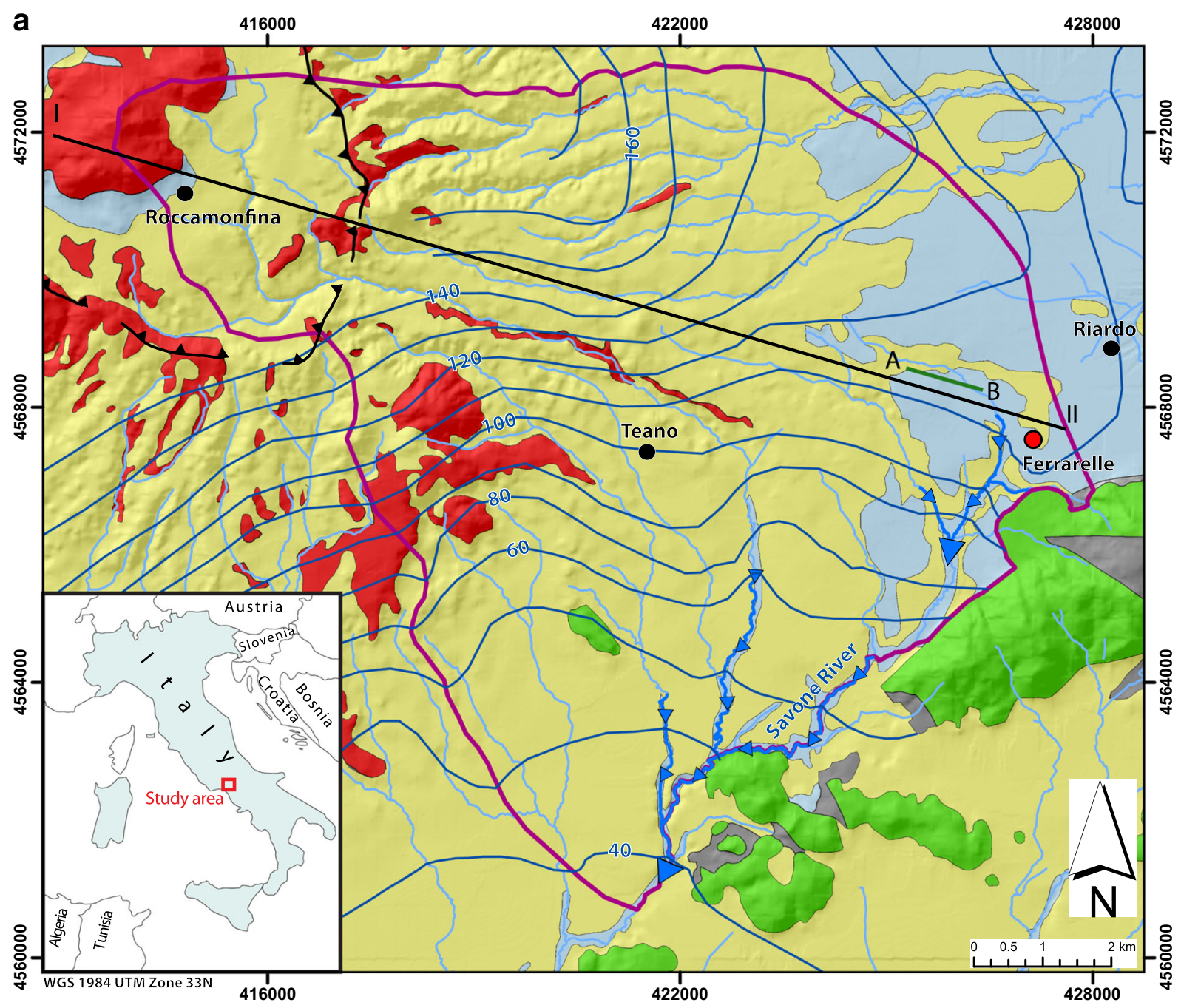

b

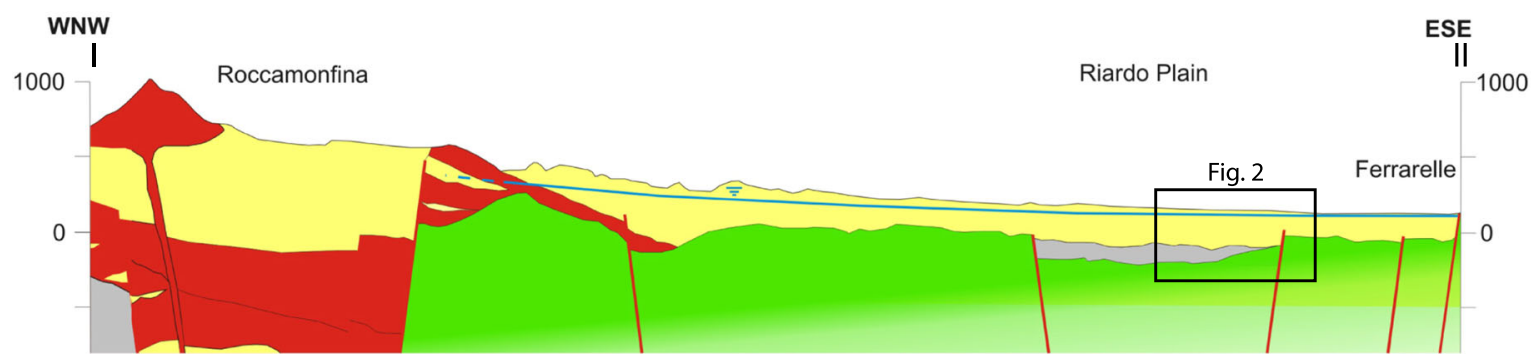

Legend

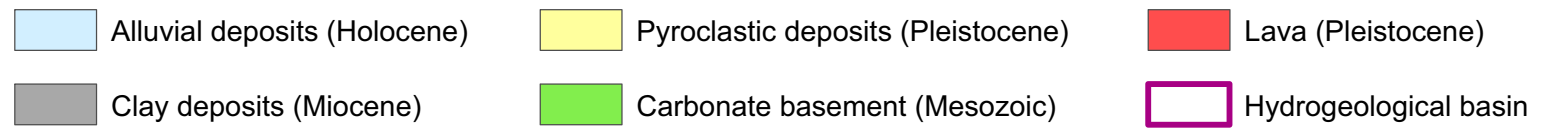

Ferrarelle S.p.A. bottling plant

Main towns $100-$ Groundwater elevation contour $(\mathrm{m}$ asl) $\sim$ Caldera rim

$\longrightarrow$ Streambed springs $\longrightarrow$ Hydrographic pattern — Cross section (Fig. 1b) — Model section (Fig. 2)

Fig. 1 a Hydrogeological map of the Roccamonfina Volcano and the Riardo Plain; b schematic geological cross section (modified from Capelli et al. 1999) 
displaced the basement via numerous horst and graben (Giordano et al. 1995; Cosentino et al. 2006; Turco et al. 2006; Boncio et al. 2016). The same carbonate units crop out in the mountain ridges (D'Argenio and Pescatore 1962) which surround the volcano edifice and the Riardo Plain (Mount Maggiore, Fig. 1).

The morphology of the carbonate basement under the volcanic deposits was mainly deduced by geophysical investigations (Capuano et al. 1992; Nunziata and Gerecitano 2012), integrated with some published and unpublished borehole data (Watts 1987; Ballini et al. 1989; Giordano et al. 1995, Saroli et al. 2017; Ferrarelle S.p.A., unpublished data, 2015). Most of the available stratigraphic data derive from sites located near Riardo Town, in correspondence with the mineral water plant. Locally, the borehole data reveal a highly deformed basement, which generally deepens from an elevation of about $110 \mathrm{~m}$ above sea level (a.s.l.) near the boundaries of the Riardo Plain, to $100 \mathrm{~m}$ below sea level (b.s.l.) moving eastward, toward the volcano edifice.

The Riardo Plain was mostly filled by the volcanoclastic and the ignimbrite units from the Roccamonfina Volcano, whose activity started around $550 \mathrm{ka}$ and ended about $150 \mathrm{ka}$ (Rouchon et al. 2008).

The complete volcanic and volcanoclastic sequence in the Riardo Plain was subdivided into four main units, which are characterised by extremely variable thickness and hydraulic conductivity, according to their depositional features:

- Campanian Ignimbrite unit (39 ka): ashy facies, characterised by low primary porosity, of the ignimbrite erupted from the Campi Flegrei volcanic district (De Vivo et al. 2001) after the end of the activity of the Roccamonfina Volcano.

- Upper pyroclastic unit (from ca. 350 to ca. $330 \mathrm{ka}$ ): alternation of reworked volcanic deposits and pumice-rich ignimbrite unit. The unit shows a good overall primary porosity and lower vertical permeability.

- Brown Leucitic Tuff ignimbrite (BLT) unit (ca. $350 \mathrm{ka}$ ): lithic tuff in ash matrix, characterised by low primary porosity (Luhr and Giannetti 1987). The unit sometimes shows a vertical fracture pattern. The unit shows variable thickness and features according to the ignimbrite deposition.

- Basal volcanoclastic unit: alternation of reworked volcanic deposits with a granular range spanning between ashes and pumices. The unit is characterised by a good overall primary porosity. The presence of layers with different porosity reduces the vertical permeability of the unit.

According to the geological framework, an upper multilayer volcanic aquifer and a deeper carbonate one can be distinguished at the regional scale. The two aquifers are separated by a noncontinuous clay unit (Flysch unit; Capelli et al. 1999). The borehole stratigraphic data, in fact, identified some areas where the volcanic deposits are directly deposited over the carbonate basement. This geological setting is in accordance with the regional geologic reconstruction of the study area (Saroli et al. 2014), in which the clays should be preserved in the graben and, in contrast, eroded on the horst.

The multilayered volcanic aquifer presents a radial flow from the Roccamonfina Volcano towards gaining streams (Savone River, Fig. 1) and is mainly recharged by direct infiltration (Celico 1983; Boni et al. 1986; Viaroli et al. 2016a, b). The boundaries of the hydrogeological basin are mainly defined along the groundwater divides of the volcanic aquifer (Fig. 1), even if the extension of the recharge of the whole aquifer system is not precisely defined because of the presence of the deep inflow. The volcanic aquifer is exploited for conjunctive uses, especially for agricultural purposes, which corresponds almost to $60 \%$ of the total groundwater requirements.

Points monitoring the carbonate aquifer are mainly clustered in the Ferrarelle S.p.A. mineral water bottling plant near Riardo Town, where the basement upraises and the fault systems allow local mixing between the carbonate and volcanic aquifers (Cuoco et al. 2010). As a result, the potentiometric levels of the two aquifers near the mixing area are very similar in absolute values and trends, related to the local seasonal thermo-pluviometric conditions.

The proposed modelling approach focuses on an area next to the Ferrarelle plant (Fig. 1). The cross section was realised using the available boreholes' stratigraphic data provided by Ferrarelle S.p.A. The local geological settings agree with the general geological framework previously described (Fig. 1b). The carbonate basement is displaced by faults forming horst and graben. The clay unit is eroded on the horst, which is directly covered by the Roccamonfina volcanic layered deposits filling the structural basin of the Riardo Plain. According to the local geological framework, the two main aquifers have been proved to be locally separated, before mixing together downgradient (Fig. 2).

The volcanic aquifer shows a low mineralisation (electrical conductivity (EC) around $350 \mu \mathrm{S} / \mathrm{cm}$ ) and $\mathrm{HCO}_{3}-\mathrm{Na}$, K water type, with a moderate amount of dissolved carbon dioxide (around $200 \mathrm{mg} / \mathrm{L}$; Cuoco et al. 2010, 2015). The mean hydraulic head, measured under static conditions in all wells tapping this aquifer layer, was around $112 \mathrm{~m}$ a.s.l.

The high mineralised carbonate aquifer (EC around $3,100 \mu \mathrm{S} / \mathrm{cm}$ ) shows $\mathrm{HCO}_{3}$-Ca water type, relatively enriched in volcanic ions $\left(\mathrm{F}^{-}, \mathrm{K}^{+}, \mathrm{As}, \mathrm{Fe}\right)$ and a high $\mathrm{CO}_{2}$ content (around $1,900 \mathrm{mg} / \mathrm{L}$ ). This aquifer shows a mean hydraulic head around $112 \mathrm{~m}$ a.s.l. with annual cycles as well.

Groundwater budget, calculated on the recharge area of the Riardo Plain aquifer in the 1992-2014 period, showed a significant water deficit (average $485 \mathrm{~L} / \mathrm{s} /$ year), without providing 


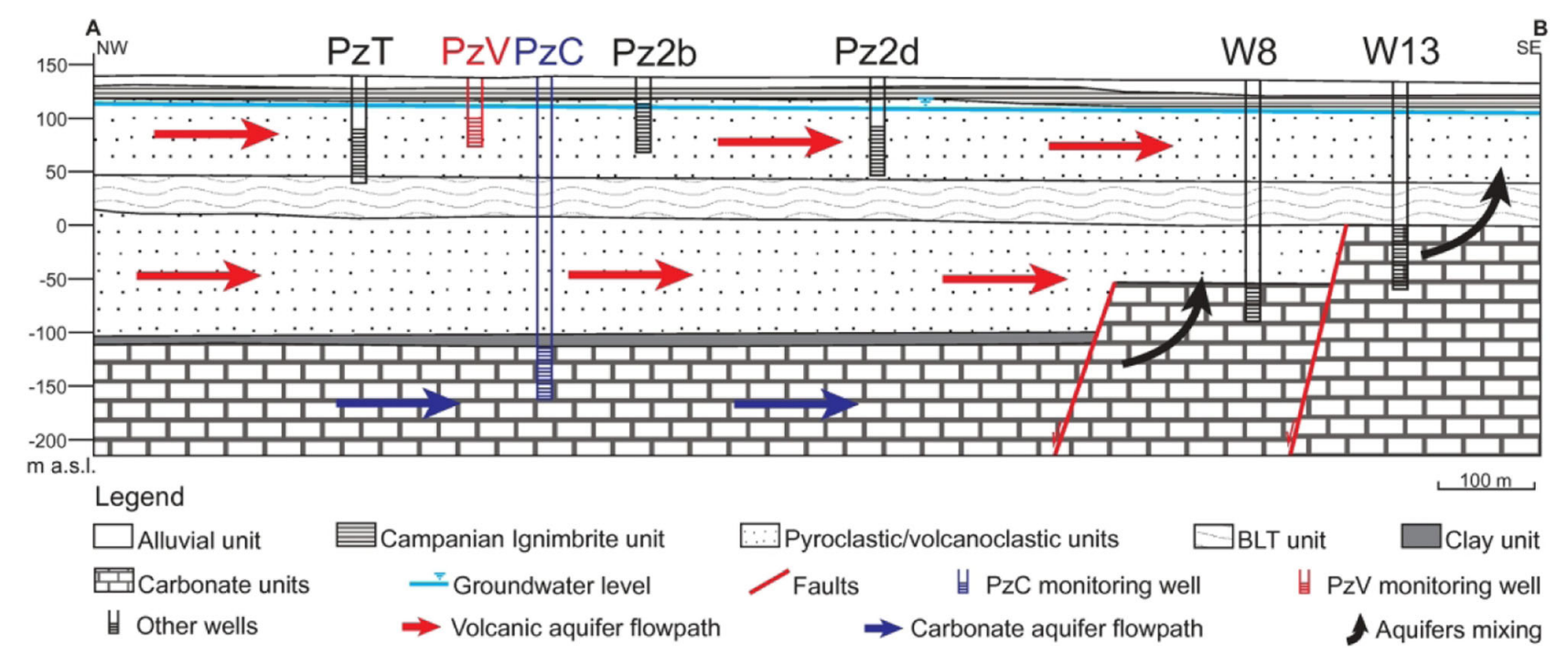

Fig. 2 Hydrogeological cross section of the modelled area (unpublished data). PzT, PzV, Pz2b and Pz2d are monitoring wells tapping the volcanic nonmineralised aquifer. $\mathrm{PzC}$ is a monitoring well tapping the carbonate mineralised aquifer. W8 and W13 are productive wells of the bottling activity

any evidence of aquifer overexploitation. In fact, in face of the calculated water deficit, the hydraulic head monitoring in the same period showed almost stable values. This result suggested the presence of an external inflow through the carbonate aquifer, probably recharged by the carbonate ridges surrounding the Riardo Plain. Direct calculation of the external recharge rate is not feasible, but it was preliminarily assumed similar to the calculated water deficit (Viaroli et al. 2018).

\section{Materials and methods}

\section{Available data and information}

\section{Hydraulic properties}

The hydraulic conductivity and the specific storage of the geological units were estimated by the interpretation of step drawdown tests and aquifer pumping tests realised in wells tapping the volcanic or the carbonate units, when available, or interpreting borehole stratigraphic data.

Time-pumping rates and time-drawdown data were processed adopting an inverse approach using the MLU 2.25 software (Hemker and Maas 1987; Hemker and Post 2010). MLU is based on an analytical solution involving Stehfest's numerical inversion of the Laplace transform and the LevenbergMarquardt algorithm for parameter optimisation (Abdelaziz and Merkel 2012; Sahoo and Jha 2017). MLU assumes a homogenous, isotropic, and uniform aquifer.

Five drawdown tests and three aquifer tests were performed in the last decade over four wells tapping the volcanic nonmineralised aquifer (upper pyroclastic unit; Fig. 2). The elaborations gave similar results in hydraulic conductivity $(5 \mathrm{~m} /$ $\mathrm{d}<k>50 \mathrm{~m} / \mathrm{d})$ and storage $\left(5 \times 10^{-3}<S>5 \times 10^{-4}\right)$, therefore, a mean value of each parameter was associated with the unit.

Pumping test data on wells tapping the basal volcanic units are not available; notwithstanding, the same initial conductivity and storage values were also associated with this zone, taking into account the similarities in the texture feature with the upper pyroclastic unit. Most of the units were considered isotropic except the upper pyroclastic and the basal volcanoclastic units, characterised by lower vertical hydraulic conductivity due to the layered alternation of volcanic deposits with a grain size ranging between ashes and pumices. A 0.1 vertical anisotropy of the conductivity coefficient was applied to these units. The hydraulic parameters of the carbonate basement were calculated from five tests conducted over the $\mathrm{PzC}$ monitoring well and another two productive wells (Fig. 2) tapping the mineralised carbonate aquifer.

\section{Head observations}

The hydraulic head observations come from the Ferrarelle S.p.A. database on the monitoring and productive wells placed in the mineral water claim area. Two monitoring wells (PzV and $\mathrm{PzC}$ ) located along the $2 \mathrm{D}$ model section were chosen as significant for the dynamics of the volcanic and carbonate portions.

$\mathrm{PzV}$ taps the non-mineralised volcanic aquifer, which is around $60 \mathrm{~m}$ depth and reaches the top of the BLT unit. The screens are located only in correspondence with the upper pyroclastic unit, whereas the uppermost units are hydraulically isolated (Fig. 2). PzV is representative of the dynamics of the volcanic aquifer, as revealed by the comparison with the datasets of other similar monitoring points (Fig. 3). In fact, the measurements of all monitoring wells tapping the non-mineralised volcanic aquifer, show a high 


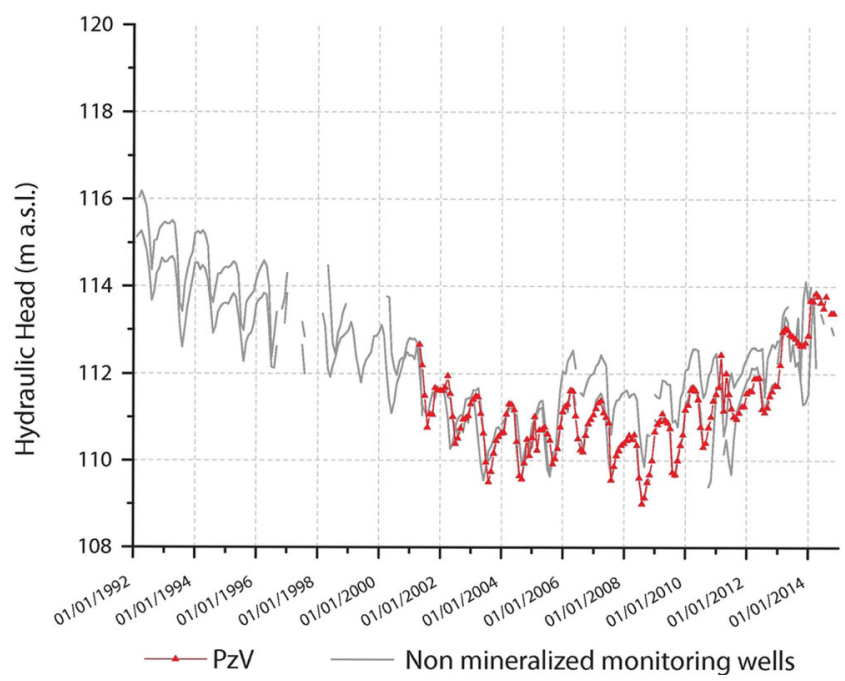

Fig. 3 Hydraulic head data collected in well PzV and in other nonmineralised monitoring wells

correlation $\left(R^{2}>0.85\right)$ and the same general trend (Fig. 3). Minor differences can be ascribed to local influence of neighbouring pumping wells. Therefore, only one available dataset was used because the similarities in value could provide an almost equal result in the calibration of the same model zone. The $\mathrm{PzV}$ dataset is composed of 255 manual measurements taken in the 2001/2014 period under static conditions.

The well PzC taps the upper portion of the carbonate mineralised aquifer, which is around $300 \mathrm{~m}$ depth and reaches "Carb zone" at around $-110 \mathrm{~m}$ a.s.l., under the volcanic sequence and clay deposits. The well is screened in the last $50 \mathrm{~m}$ in the carbonate units (Fig. 2). The $\mathrm{PzC}$ hydraulic head dataset is composed of 285 manual measurements taken between 2000 and 2014 under static conditions. The other wells tapping the same portion of the aquifer are productive wells. The hydraulic head data are therefore affected by the pumping activity and are not taken into account for the model calibration procedure. The reliability of the $\mathrm{PzC}$ dataset to describe the carbonate portion of the aquifer is confirmed by the comparison of the observations with similar monitoring wells placed in other portions of the claim area (Fig. 4).

\section{Numerical methods and processing}

The 2D finite element numerical model was implemented using the FEFLOW code (Trefry and Muffels 2007), which applied the finite element approach to the calculation of the flow, mass and heat transport simulations. The numerical model was calibrated via inverse modelling through FePEST (graphical user interface of the PEST code; Doherty 2010).

PEST performs the parameter estimation, minimising the discrepancies between simulated and measured data expressed as objective function. The objective function $(\Phi)$ represents the sum of squared-weighted residuals, expressed by the following relationship:

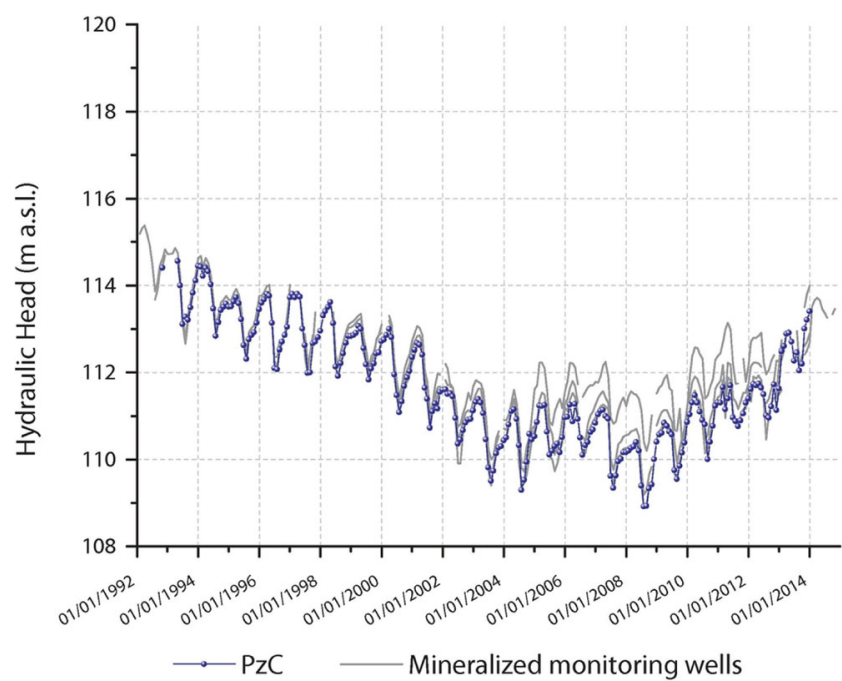

Fig. 4 Hydraulic head data collected in well $\mathrm{PzC}$ and in other mineralised monitoring wells

$\Phi=\sum_{i=1}^{m}\left[w_{i}\left(c_{i}-c_{i}^{\prime}\right)\right]=\sum_{i=1}^{m}\left(w_{i} r_{i}\right)^{2}$

where $w_{i}$ is the weight of the $i$ th observation, $c_{i}$ is the $i$ th observation, $c_{i}^{\prime}$ is the simulated value corresponding to $c_{i}, r_{i}$ is the residual value, $m$ is the number of observations.

Calibration over the hydraulic conductivity zones was preliminarily performed under steady-state conditions, using the mean hydraulic head values for the $\mathrm{PzC}$ and $\mathrm{PzV}$ observation points. The mean zenithal recharge value was applied as Neumann BC. The parameter ranges for the zones defined by pumping tests were set as \pm one order of magnitude of the initial value of hydraulic conductivity. A wider range defined by reliable parameter values was associated to the other zones. The steady-state calibration results were used to perform the transient calibration, applying the same bounds of calibration for the hydraulic conductivity and adding the storage as a parameter to be estimated. The model was calibrated according to 24 mean monthly hydraulic head values measured in $\mathrm{PzC}$ and $\mathrm{PzV}$ during 2003.

Along with the calibration process, sensitivity analysis was performed. Ranking the parameters according to their sensitivity, simpler versions of the model were calibrated selecting different numbers of parameters with higher sensitivities. After the calibration, the models were validated over the 2000-2014 interval, according to about 360 hydraulic head observations. Residuals, observation sensitivities and information criteria were calculated for each calibration run. Comparison among the different results allowed the ranking of versions of the model drawing more information based on the available data, without overfitting the observations, in accordance with the principle of parsimony.

This principle attests that as the number of parameters increases in a model, the calibration improves, but not the model reliability because the model starts to reproduce not only the 
behaviour of the physical system, but also the noise associated with the data. Therefore, there should be a balance between the quantity of data and the number of parameters that can be calibrated, as expressed by the information criteria.

In a first version of the model, the deep inflow was set according to the preliminary conceptual model described in Viaroli et al. (2018). Another eight versions of the model with different bottom inflow were implemented and calibrated following the same procedure, in order to define the sensitivity of the deep inflow and to define a possible range for this fundamental unknown.

The bottom recharge was kept constant along the simulation period, since it was assumed that time variability of deep circuits is negligible with respect to the direct infiltration. The direct infiltration was applied on a monthly basis according to the budget time series. Therefore, the conceptual model tested was that the wavelength, frequency and trend of hydraulic head oscillations are only a function of the volcanic aquifer, which is directly affected by the zenithal recharge, while the absolute average head value ( $m$ a.s.l.) is given by the combination of the direct infiltration and the deep inflow through the carbonate basement.

Highly parametrised methods associated with Null-Space Monte Carlo (NSMC) analysis applied to the groundwater modelling (Tonkin and Doherty 2009; Herckenrath et al. 2011; Anderson et al. 2015; Alberti et al. 2018) could provide better insights about the uncertainty associated with the model predictions, enabling the model to fit the observed data with a stochastic distribution of parameters. Nevertheless, given the limited extension of the 2D model domain, its simplified and relatively known geometry, and its vertical dimension, the classical manual regularisation of parameters was performed through hydraulic conductivity zones definition. Without mathematical regularisation used in the highly parametrised approach, NSMC is not applicable.

\section{Model complexity definition using information criteria}

Hydrologic environments are complex systems that can be described by numerical simulators, but with difficulty. Multiple interpretations and mathematical descriptions can exist for the same context, regardless of the quantity and quality of available data. Different hydrogeological models can focus on different aspects of a system, isolating or neglecting the aspects which are not relevant to the aim of the numerical model. If the illusion of the "perfect simulator" is nevertheless pursued, models can suffer the nonuniqueness of the numerical solution. The best way to control this limit is to apply the mathematical regularisation to the spatial distribution of the parameters, entering the domain of the highly parametrised approach. In cases where the geology is well defined and the model structure is kept relatively simple, a parsimonious model can be built in an attempt to provide good model performances with as few calibrated parameters as possible (Engelhardt et al. 2014). There are different approaches to define the better compromise between a good model performance and a limited number of calibrated parameters (Massmann et al. 2006; Hill and Tiedeman 2007; Engelhardt et al. 2014). One of these approaches is based on the definition of the information criteria such as Akaike information criterion (AIC; Akaike 1973), the Bayesian information criterion (BIC; Schwarz 1978) and Kashyap's information criterion (KIC; Kashyap 1982). These criteria discriminate between models based on how closely they reproduce hydrologic observations (favouring models that reproduce observed behaviour most closely) and how many parameters they contain (penalising models that contain too many; Ye et al. 2010). The criteria applied herein are reported in the following.

Akaike's information criterion (AIC) The AIC selects a parsimonious model which considers the smallest number of parameters needed to provide an adequate approximation of the measured data. In the case of normally distributed residuals (obtained by parameter estimation through PEST in this work), AIC is defined as follows (Ye et al. 2008; Engelhardt et al. 2014):

$\mathrm{AIC}=n \ln \left(\hat{\sigma}^{2}\right)+n \ln (2 \pi)+n+\ln \left|Q^{-1}\right|+2 p$

where $p$ equals the number of calibrated parameters of the model plus one ( $p=K+1$, where $K$ corresponds to the number of parameters), $n$ the number of observations, $Q$ the weight matrix, and $\hat{\sigma}^{2}$ represents an estimation of the variance of weighted residuals, which is given by:

$\hat{\sigma}^{2}=\frac{\sum_{j=1}^{n}(\varepsilon q)_{i}^{2}}{n}$

where $\varepsilon$ corresponds to the residuals (observed minus calculated values) and $q$ is the weight of the $j$ th observation, which is herein set equal to 1 for all observations.

Bayesian information criterion (BIC) The BIC provides a further comparison between models with a different number of calibrated parameters, in particular where the AIC suggests the use of a greater number of parameters than required (Hill and Tiedeman 2007). The BIC is calculated by PEST according to the equation (Doherty 2012):

$\mathrm{BIC}=n \ln \left(\hat{\sigma}^{2}\right)+p \ln (n)$

where the terms used are the same as described for the AIC.

Kashyap's information criterion (KIC) The KIC, unlike previous indexes, considers the sensitivity of the parameters, in light of their initial values. This ability is given by the presence 
of the Jacobian matrix within the equation. KIC weighs and classifies alternative models with respect to the predictive performance of the models through cross-validation of the dataset of initial hydraulic parameters (Ye et al. 2008). The KIC index was derived from Kashyap (1982) and in PEST it is calculated as follows (Doherty 2012):

$\mathrm{KIC}=[n-(p-1)] \ln \left(\hat{\sigma}^{2}\right)-(k-1) \ln (2 \pi)+\ln \left|J^{t} Q J\right|$

where $J$ is the Jacobian matrix, $Q$ the weight matrix and $J^{t} Q J$ the normal matrix. The other terms are the same as in the previous criteria.

\section{Model performance evaluation}

The performance assessment is based on different residual statistics and is considered satisfactory when observations and simulated values are in good agreement. The evaluation of the 2D model was performed according to five statistical indices described in the literature:

- The root mean square error (RMSE) provides a quantitative measure of the model error expressed in the units of the variable. When it is equal to 0 , it indicates a perfect correspondence between observed and simulated values; the increase in RMSE values indicates an increasingly poor correspondence.

$\mathrm{RMSE}=\sqrt{\frac{\sum_{i=1}^{n}\left(P_{i}-O_{i}\right)^{2}}{n}}$

where $n$ corresponds to the number of the observations, $P_{i}$ the $i$ th simulated value and $O_{i}$ the $i$ th observed value.

- The Nash-Sutcliffe Model Efficiency (NSE; Nash and Sutcliffe 1970) considers the ratio of the model error to the variability of the data. Nash-Sutcliffe efficiencies can range between $-\infty$ and 1 . Values between 0 and 1 are generally viewed as acceptable levels of performance, whereas values less than 0 indicate unacceptable performance. An efficiency of 1 corresponds to a perfect match between model and observations, whereas a value close to zero indicates that the model predicts individual observations no better than the average of the observations. Nevertheless, NSE values higher than 0.65 denote an excellent match (Adamowski and Chan 2011; Golmohammadi et al. 2014; Matiatos et al. 2014).

$\mathrm{NSE}=1-\frac{\sum_{i=1}^{n}\left(O_{i}-P_{i}\right)^{2}}{\sum_{i=1}^{n}\left(O_{i}-\bar{O}\right)^{2}}$

where $n$ corresponds to the number of the observations, $P_{i}$ the $i$ th simulated value and $O_{i}$ the $i$ th observed value. $\bar{O}$ corresponds to the mean observed data.
- Pearson correlation coefficient $(R)$ indicates the strength and direction of a linear relationship between two variables (in this study, observed and simulated values). The correlation is +1 in the case of a perfect increasing linear relationship and -1 in the case of a decreasing linear relationship. The values in between indicate an intermediate correlation degree, a value higher than 0.7 denotes a significant correlation (Tichy 1993):

$$
R=\frac{\sum_{i=1}^{n}\left(O_{i}-\bar{O}\right)^{2}\left(P_{i}-\bar{P}\right)^{2}}{\sqrt{\sum_{i=1}^{n}\left(O_{i}-\bar{O}\right)^{2}} \sqrt{\sum_{i=1}^{n}\left(P_{i}-\bar{P}\right)^{2}}}
$$

where $n$ corresponds to the number of the observations, $P_{i}$ the $i$ th simulated value and $O_{i}$ the $i$ th observed value. $\bar{O}$ corresponds to the mean observed data and $\bar{P}$ corresponds to the mean simulated value.

- The RMSE-observations standard deviation ratio (RSR) corresponds to the ratio of the RMSE and standard deviation of measured data. RSR varies from the optimal value of 0 , to a large positive value. The lower RSR depends on good model simulation performance and therefore on low RMSE value. The ratio is expressed as follows:

$$
\mathrm{RSR}=\frac{\mathrm{RMSE}}{\mathrm{SD}_{\mathrm{obs}}}=\left[\frac{\sum_{i=1}^{n}\left(O_{i}-P_{i}\right)^{2}}{\sqrt{\sum_{i=1}^{n}\left(O_{i}-\bar{O}\right)^{2}}}\right]
$$

where $n$ corresponds to the number of the observations, $P_{i}$ the $i$ th simulated value and $O_{i}$ the $i$ th observed value. $\bar{O}$ corresponds to the mean observed data.

- When the average of residuals is far from zero, the residuals present a bias. The bias can be normalised (NBI) to quantify the relative departure from simulated and observed values:

$\mathrm{NBI}=\frac{(\bar{P}-\bar{O})}{\bar{O}}$

where $\bar{P}$ corresponds to the mean simulated value and $\bar{O}$ corresponds to the mean observed data.

The aforementioned statistical descriptors of the residuals were calculated for all the different versions of the model (nine model scenarios with different deep inflow rates). The comparison of the results allowed the definition of a range of more reliable results in the deep inflow estimation.

\section{Post-calibration matrices}

At the end of the elaborations on the validation model, PEST provides three matrices: the post-calibration 
parameter covariance matrix, the parameter correlation coefficient matrix, and the matrix of eigenvectors of the parameter covariance matrix (the latter two matrices being derived from the first).

The post-calibration covariance matrix is calculated using equation:

$$
C\left(\hat{p}^{-} p\right)=\sigma_{r}^{2}\left(J^{t} Q J\right)^{-1}
$$

where $\hat{p}$ is the estimated parameter, and $p$ the real parameter (Doherty 2015)

The uncertainties calculated in this way take no account of the manual regularisation that is normally required to formulate a well-posed inverse problem. The covariance matrix is always a square symmetric matrix with as many rows (and columns) as the adjustable parameters. The variances and covariances reported in the covariance matrix are valid only if the linearity assumption upon which their calculation is based is valid. The diagonal elements of the covariance matrix are the post-calibration variances of adjustable parameters. The off-diagonal elements of the covariance matrix represent the covariances between parameter pairs.

The correlation coefficient matrix is calculated from the post-calibration covariance matrix using equation:

$\rho_{i j}=\frac{\sigma_{i j}}{\sigma_{i} \sigma_{j}}$

where $\sigma_{i j}$ is the covariance between $\mathbf{x}_{i}$ and $\mathbf{x}_{j}$ components of the random vector $\mathbf{x}$ (Doherty 2015). The diagonal elements of the correlation coefficient matrix are always unity; offdiagonal elements are always between 1.0 and -1.0 . The closer that an off-diagonal element is to 1.0 or -1.0 , the more highly correlated the parameters corresponding to the row and column numbers of that element.

As is pointed out by Doherty (2015), while the information contained in the correlation coefficient matrix has the potential to inform whether the inverse problem is currently ill-posed (or is approaching this condition), and whether excessive parameter correlation is responsible for this condition, in practice, values calculated for elements of this matrix can often be deleteriously affected by the very ill-posedness that they seek to expose.

The eigenvalues and eigenvectors of the post-calibration covariance matrix are a far more reliable source of information in this regard.

The eigenvector matrix is composed of as many columns as there are adjustable parameters, each column containing a normalised eigenvector of the post-calibration covariance matrix. Because a covariance matrix is positive-definite, these eigenvectors are real and orthogonal; they represent the directions of the axes of the postcalibration probability "ellipsoid" in the $m$-dimensional space occupied by the $m$-adjustable parameters. The square root of each eigenvalue is the length of the corresponding semi axis of the post-calibration probability ellipsoid in $\mathrm{m}$ dimensional adjustable parameter space. If the ratio of a particular eigenvalue to the lowest eigenvalue of the postcalibration covariance matrix is particularly large, then the respective eigenvector defines a direction of relative insensitivity in parameter space. The eigenvector pertaining to the highest eigenvalue is particularly worthy of attention in many parameter estimation problems, for this defines the direction of maximum insensitivity, and is hence of greatest elongation of the postcalibration probability ellipsoid in adjustable parameter space. The ratio (called condition number; Carrera and Neuman 1986a) of the highest to lowest eigenvalue of the postcalibration covariance matrix is of particular importance. If it is too high, then inversion of this matrix becomes numerically difficult (leading to a spurious inverse matrix), or even impossible. In the parameter estimation context, this is an outcome of the fact that solution of the inverse problem approaches nonuniqueness as elongation of the postcalibration parameter probability ellipsoid increases to infinity.

\section{Model building}

\section{Model mesh and properties}

The 2D model focuses on a small but significant section located west of the Ferrarelle S.p.A. mineral bottling plant where it is possible to understand the dynamics, which regulates the aquifer of the Riardo Plain that sources the mineral water. The model section is located in the unique area (Fig. 1) where it is possible to separately distinguish and monitor the volcanic and carbonate aquifer. The carbonate aquifer, covered by the volcanic units, is elsewhere too deep to be exploited or monitored. Furthermore, moving westward, where the carbonate basement upraises due to the tectonic settings, the aquifer dynamics depend on the mixing of the two aquifer layers (Fig. 2).

The model mesh is defined by 4,990 square elements $(10 \mathrm{~m} \times 10 \mathrm{~m})$. The vertical slice is around $1,500 \mathrm{~m}$ length and $300 \mathrm{~m}$ deep (from around $140 \mathrm{~m}$ a.sl. to around $-160 \mathrm{~m}$ a.s.1.), according to the $\mathrm{PzC}$ stratigraphic log. The top of the slice was set as horizontal since no significant variations in the ground elevation are present along the section, if compared to its total thickness.

The local geological setting of the modelled area was defined using borehole stratigraphic data provided by Ferrarelle S.p.A. In the eastern section of the model, the limestone basement was detected at an elevation of around $30 \mathrm{~m}$ a.s.l., directly covered by volcanic deposits. Moving westward the basement is progressively deepened by extensive tectonic activity. In fact, 
it was detected at an elevation of around $-110 \mathrm{~m}$ a.s.l. in the western portion of the model, covered by around $20 \mathrm{~m}$ of clay deposits and by $240 \mathrm{~m}$ of volcanic deposits (Fig. 5).

The model was divided into 11 zones approximately defined according to the described geological framework (unpublished data; Fig. 5):

- L1 zone corresponds to the detrital and alluvial deposits, with grain sizes ranging between clays to sands, and has a mean thickness of around $10 \mathrm{~m}$

- L2 zone corresponds to the Campanian Ignimbrite unit and has a mean thickness of around $10 \mathrm{~m}$

- Pt zone corresponds to the upper pyroclastic unit with a mean thickness of around $60 \mathrm{~m}$

- BLT zone corresponds to the mean thickness (around $40 \mathrm{~m}$ ) of the BLT unit in the central and western section of the model

- BLT_dx zone corresponds to the eastern portion of the BLT unit, which locally covers the carbonate basement; it appears highly fractured then more permeable

- Pi zone corresponds to the basal volcanoclastic unit; it shows a variable thickness from around $100 \mathrm{~m}$ up to $0 \mathrm{~m}$ moving eastward, due to the upraise of the carbonate basement

- Clay zone corresponds to 20 m clay unit which covers the carbonate units in the western sector of the plain and is interrupted in the eastern sector where the carbonate basement upraises

- Carb zone corresponds to the limestone units; its geometry is provided by borehole data

- F1 zone and F2 zone represent two portions of the "Carb zone" reproducing fault areas and is located at the edge of the basement steps and are expected to present a higher hydraulic conductivity

- $B C$ zone corresponds to the eastern column of the model and does not have a physical meaning as it was only used to allow the positioning of the Dirichlet boundary condition at a short distance, even if the real outflow of the system is much farther, maintaining the small dimensions of the model domain; its role can be considered similar to the conductance defined in the General Head Boundary condition in MODFLOW

The hydraulic conductivity and the specific storage of the 11 zones were estimated by the interpretation of borehole stratigraphic data or, if available, by interpretation of step drawdown tests and aquifer pumping tests. The elaborated pumping tests were conducted on wells tapping the limestone units (Carb zone) and the upper pyroclastic unit (Pt zone) aquifer. No pumping tests are available on the basal volcanoclastic unit (Pi zone) but the same initial values were assigned according to the similarities with the Pt zone. The initial values of the hydraulic parameters are reported in Table 1.

\section{Boundary conditions}

\section{Input}

The direct recharge of the volcanic aquifer was calculated by Viaroli et al. (2018) elaborating the daily thermo-pluviometric data from eight meteorological stations (Regione Campania, unpublished data, 2015; Ferrarelle S.p.A., unpublished data, 2015) during the 2000-2014 period. Two meteorological stations are placed within the Riardo Plain hydrogeological basin, in correspondence of the Roccamonfina Town and the Ferrarelle S.p.A. mineral water bottling plant (Fig. 1). The other six stations (Cellole, Grazzanise, Pontelatone, Presenzano, Rocca d'Evandro and Sessa Aurunca) are placed around the study basin and cover an area of approximately $900 \mathrm{~km}^{2}$. The rainfall data show a wide variability during the study period, with mean annual values ranging between $580 \mathrm{~mm}$ in 2000 and $1,600 \mathrm{~mm}$ in 2009 .

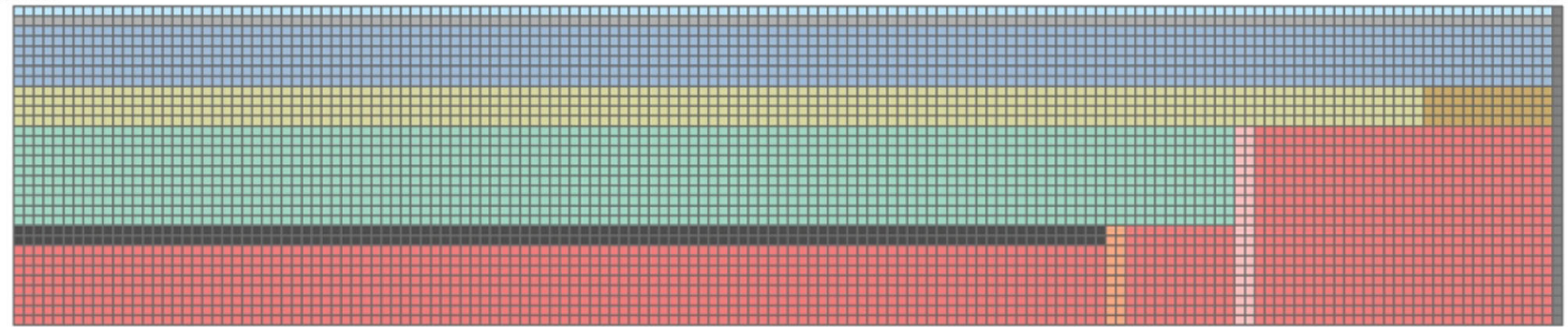

Legend
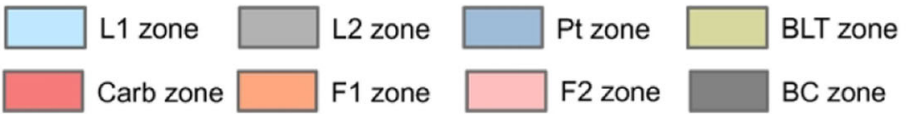

$100 \mathrm{~m}$

Fig. 5 Model grid and zones (Viaroli et al, Roma Tre Univerisity (Italy), unpublished data, 2018) 
Table 1 Initial values of hydraulic conductivity and storage

\begin{tabular}{lclll}
\hline Model zone & $\begin{array}{l}\text { Hydraulic conductivity } \\
(\mathrm{m} / \mathrm{d})\end{array}$ & $\begin{array}{l}\text { Hydraulic conductivity } \\
(\mathrm{m} / \mathrm{s})\end{array}$ & $\begin{array}{l}\text { Specific storage } \\
\text { Vertical anisotropy } \\
\text { of conductivity }\end{array}$ \\
\hline L1 zone & 0.0864 & $1 \times 10^{-6}$ & $1 \times 10^{-4}$ & 1 \\
L2 zone & 0.0864 & $1 \times 10^{-6}$ & $1 \times 10^{-4 a}$ & 1 \\
Pt zone & $30^{\mathrm{a}}$ & $3.5 \times 10^{-4 \mathrm{a}}$ & $1 \times 10^{-4}$ & 0.1 \\
BLT zone & 0.0864 & $1 \times 10^{-6}$ & $1 \times 10^{-4}$ & 1 \\
BLT_dx zone & 20 & $2.3 \times 10^{-4}$ & $1 \times 10^{-4 a}$ & 1 \\
Pi zone & $30^{\mathrm{a}}$ & $3.5 \times 10^{-4 a}$ & $1 \times 10^{-4}$ & 0.1 \\
Clay zone & 0.000864 & $1 \times 10^{-8}$ & $1 \times 10^{-7 \mathrm{a}}$ & 1 \\
Carb zone & $17^{\mathrm{a}}$ & $2 \times 10^{-4 \mathrm{a}}$ & $1 \times 10^{-4}$ & 1 \\
F1 zone & 100 & $1.1 \times 10^{-3}$ & $1 \times 10^{-4}$ & 1 \\
F2 zone & 100 & $1.1 \times 10^{-3}$ & $1 \times 10^{-4}$ & 1 \\
BC zone & 0.008 & $1 \times 10^{-7}$ & 1 \\
\hline
\end{tabular}

The conductivity values are reported both in $\mathrm{m} / \mathrm{s}$ and in converted units for the numerical model $(\mathrm{m} / \mathrm{d})$

${ }^{a}$ Hydraulic conductivity and storage values calculated by pumping test elaborations

The monthly actual evapotranspiration, the water surplus and the water deficit calculated by the Thornthwaite's method (Thornthwaite and Mather 1955), highlight similar climatic trends in all weather stations. The mean recharge period was generally identified from November to April. Considering the existing correlation of the weather variables with the ground elevation, cokriging was applied to spatialize the data over the studied basin using GIS.

The effective infiltration, corresponding to the evaluable recharge, was calculated as percentage of the water surplus, taking into account both the permeability of the hydrogeological complexes outcropping in the basin and the slope of the ground surface. In the study area, the effective infiltration was estimated at $55 \%$ of the water surplus, according to Viaroli et al. (2018).

The contribution of the irrigation return flow was not considered in this model, since approximately $70 \%$ of the irrigated areas corresponds to fruit trees and irrigation losses are eliminated using drip irrigation techniques (Maréchal et al. 2006). A mean recharge value was applied to the nodes of the first row of the model as Neumann boundary condition (Fluid flux BC) during the steady-state simulation (Fig. 6). The time scheme of the transient simulation included a daily discretisation. The recharge, calculated at monthly scale, was applied to each day as the monthly value divided by the number of the days of the pertinent month.

The recharge of the carbonate aquifer, still difficult to evaluate, is likely to up-flow from the deep reservoir, according to the hydrogeological conceptual model (Viaroli et al. 2018) under numerical validation in this work. The bottom recharge was applied as a constant value using the Neumann boundary condition applied to the nodes of the lower nodes of the mesh, falling within the carb zone (Fig. 6). Different inflow rates are then tested in another eight model scenarios, with an increasing/decreasing percentage of the original tested inflow. The reliability and efficiency of the simulated deep inflow rate and its constancy during the simulated period are evaluated using statistical indexes.

\section{Output}

A Dirichlet boundary condition of $109 \mathrm{~m}$ a.s.l. was applied to the eastern boundary column of the model, according to the lower hydraulic head value measured in $\mathrm{PzV}$ and $\mathrm{PzC}$ (Figs. 3 and 4). No inflow is allowed from the applied boundary condition through the addition of a constrain.

Most of the groundwater withdrawals in the study area are for irrigation purposes. No detailed information about the quantification and the time interval of the agricultural withdrawals is available because the majority of irrigation was carried out using private wells without any official information. The agricultural withdrawals were evaluated in the 2000-2014 period according to local climatic conditions elaborated at monthly scale by Thorntwaithe's method and the land use information (Viaroli et al. 2018). The presence of water deficit was detected every year in July and August; it implies the absence of available water in the soil, and the evapotranspiration exceeding the rainfall amount. Thus, the plantations are likely to be irrigated to avoid the plant exsiccation. The groundwater required for the plant growth was set equal to the water deficit. This method allows only an estimation of the agricultural withdrawals due to the absence of an 


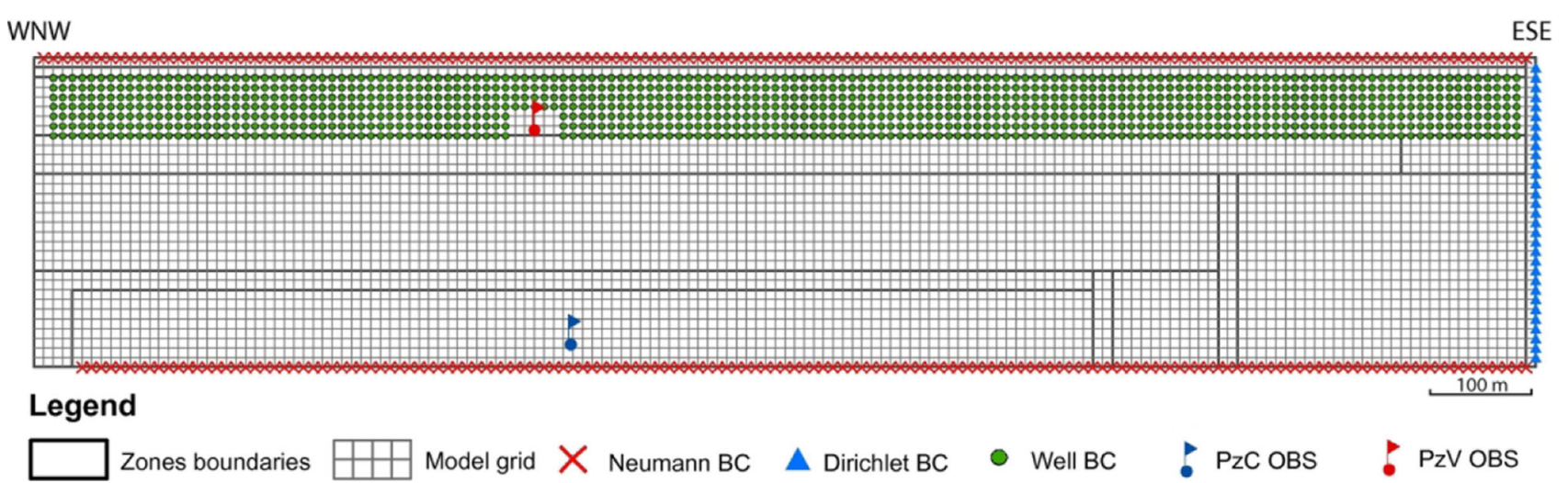

Fig. 6 Hydraulic head observation points and the boundary condition applied to the model

official dataset; therefore, exceeding or minor extractions could not be estimated.

In the 2D model, the effect of the agricultural withdrawals was recreated using the well boundary condition (well BC) uniformly scattered on the portion of the volcanic aquifer exploited by most of the agricultural wells. The estimated monthly withdrawal, calculated as the water deficit over the model area, was divided and applied on the 1,056 nodes of the Pt zone (Fig. 6).

Even if the calculated water deficit occurred in July and August, the irrigation period usually occurs from June to September according to the regional directive of groundwater use. The assumed agricultural requirements were then spread over a wider period.

\section{Modelling process results}

The results of the articulated modelling workflow are herein described. In order to clarify the steps that were followed, two flowcharts are included in the paragraph. In the first phase (Fig. 7), the steady-state model was calibrated over the hydraulic conductivity, according to the average hydraulic head value for each monitoring point (MOD0). The Neumann boundary conditions were applied as average values and the irrigation withdrawals (well BC) neglected.

The bottom recharge was applied according to the conceptual model proposed in Viaroli et al. (2018), i.e. $-0.0004 \mathrm{~m} / \mathrm{d}$, which corresponds to around $480 \mathrm{~L} / \mathrm{s}$. The calibrated hydraulic conductivities approached the order of magnitude determined by the pumping tests, used as prior information.

The steady-state model was then turned into a transient model, considering data collected during 2003 (MOD1). The inflow through the carbonate basement was kept at the same constant rate as the previous phase. The direct recharge was varied in time introducing the monthly average time series. The reconstructed irrigation withdrawal time series (well BC) was also applied to the model. Before calibrating the transient model, the sensitivity of the 22 parameters was calculated though PEST. Ranking the parameters according to their sensitivity, seven versions of the model were set up and characterised by an increasing number of adjustable parameters (Fig. 8).

The MOD1 model was calibrated over the hydraulic head measured in the $\mathrm{PzC}$ and $\mathrm{PzV}$ wells during 2003; calibration was performed seven times considering the increasing number of parameters. Each calibrated version of the MOD1 was then validated over the complete dataset of hydraulic head measurements collected between 2000 and 2014, in order to control the goodness of the simulation. The values of $\Phi$ and the information criteria (AIC, BIC and $\mathrm{KIC}$ ) were compared to identify the model version containing the most information with respect to the number of calibrated parameters (Fig. 9).

According to the results shown in Fig. 9, it is possible to choose the more efficient version based on the lower $\Phi$ value and the lower information criteria values in the model calibrated with the full number of adjustable parameters (22). The values of the calibrated parameters are shown in Table 2.

The selected version of the model was run to simulate the 2000-2014 interval (around 5,000 days). The simulated and measured data are shown in Fig. 10. The model is able to reproduce the general trend of the aquifer, which superimposes the annual oscillation of both the volcanic and carbonate portion of the aquifer, confirming the reliability of the conceptual model, which is the main objective of the research. Minor errors could be identified, related to the discretisation of the boundary conditions. The minimum annual head values, for example, occur during the summer and sometimes they are overestimated by the model simulation. This discrepancy is probably related to the estimation of the agricultural withdrawals only based on climatic data as described in section 'Output'. Exceeding groundwater extraction could not be, therefore, evaluated a priori due to the absence of official withdrawal rates. The correspondence of the peaks is sometimes not exact due to the nonuniform distribution of the groundwater extraction rate during the irrigation period different to the applied Well BC time series. The over estimation of the 


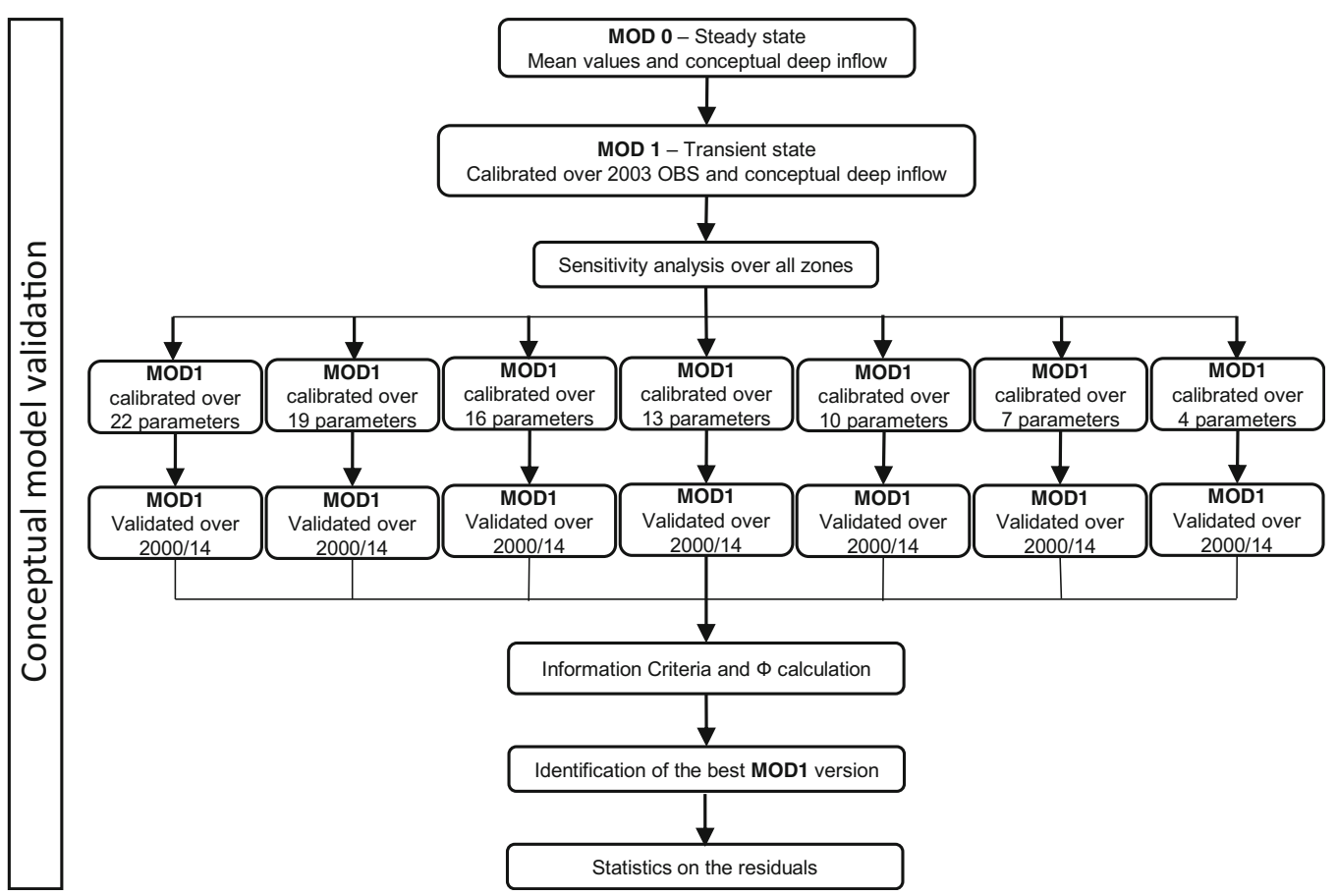

Fig. 7 Flowchart describing the activities of the first phase of the model elaboration

minimum head data could imply a following overestimation on the next recharge period. Well $\mathrm{BC}$ could also be manually calibrated in order to fit the measured data, but the agricultural withdrawals estimation was maintained as described in the text because it is an objective and replicable method.

The residuals (calculated as the difference between the simulated and measured hydraulic head levels) were used to elaborate the statistical indexes described in the model performance evaluation paragraph. The six statistical indexes were not only calculated on the entire dataset (540 mean monthly hydraulic head measurements) of each model but also distinguishing the $\mathrm{PzV}$ and $\mathrm{PzC}$ data (Table 3).

The statistics of the results reported in Table 3 show a good model performance $(\mathrm{NSE}=0.6)$, correlation $(R=0.77)$ and a small root mean square error $(\mathrm{RMSE}=0.51)$. In addition, the model in 14 years of simulation does not show any bias (NBI $\sim 0$ ). Focusing on the statistics of each monitoring well, the results are comparable confirming a good simulation of both the volcanic and the carbonate hydraulic head values.

According to the reliability of the statistical results, the groundwater budget has been calculated on the MOD1 version during the validation period 2000-2014. It is possible to calculate the volume of cumulated inflow or outflow from each boundary condition applied to the model (Table 4) by using the FEFLOW software.

Groundwater inflows and outflows are in balance. The differences in storage are minimal according to the long-term simulation. The term of simulated recharge via Neumann $\mathrm{BC}$ corresponds both to the portion of water infiltrated by zenithal recharge and to the deep inflow contribution. By means of a zonal budget calculation, it is possible to distinguish the quantity of water that can be attributed to each of the two recharges (Table 4).

The zonal budget results highlight the amount of deep inflow, which corresponds to around $38 \%$ of the total recharge.

The second phase of the process (Fig. 11), considered another eight model scenarios where the deep inflow was changed between 0 (no flux) and $-0.004 \mathrm{~m} / \mathrm{d}$ (one order of magnitude higher than the MOD1; the negative sign conventionally indicates inflow in FEFLOW), in order to analyse the model response. The detail of the deep inflow applied to each model scenario is reported in Table 5 . The calibration procedure in each case is the same as described for MOD1.

The most efficient model version was identified according to the $\Phi$ and information criteria of models calibrated with an increasing number of adjustable parameters. The best model version of each model scenario was used to calculate the statistics of the residuals over the complete monitoring series (Table 6).

The groundwater budget was calculated for all MOD versions during the validation period 2000-2014. The volume of the total cumulated inflow and the zonal budget was calculated in order to define the contribution of the deep inflow to the recharge of the different model scenarios (Table 7). 


\begin{tabular}{|c|c|c|c|c|c|c|c|c|c|}
\hline Parameter & \begin{tabular}{|c|}
$\begin{array}{c}\text { Initial value } \\
(\mathrm{m} / \mathrm{d})\end{array}$ \\
\end{tabular} & Sensitivity & 4 & 7 & 10 & 13 & 16 & 19 & 22 \\
\hline$k-B C$ & $8 \times 10^{-3}$ & 0.552 & \multirow{22}{*}{\multicolumn{2}{|c|}{$\mathrm{T} T$}} & \multirow[t]{22}{*}{$T$} & \multirow{22}{*}{\multicolumn{2}{|c|}{7}} & \multirow[t]{22}{*}{$\mathrm{T}$} & \multirow[t]{22}{*}{$\mathrm{T}$} \\
\hline $\mathbf{S}-\mathbf{P i}$ & $1 \times 10^{-4}$ & 0.543 & & & & & & & \\
\hline S - Pt & $1 \times 10^{-4}$ & 0.480 & & & & & & & \\
\hline S - BLT & $1 \times 10^{-4}$ & 0.451 & & & & & & & \\
\hline k-BLT & $8.64 \times 10^{-2}$ & 0.107 & & & & & & & \\
\hline$S-L 2$ & $1 \times 10^{-4}$ & 0.090 & & & & & & & \\
\hline k-Carb & 17 & 0.077 & & & & & & & \\
\hline S - L1 & $1 \times 10^{-4}$ & 0.069 & & & & & & & \\
\hline S - Clay & $1 \times 10^{-4}$ & 0.066 & & & & & & & \\
\hline $\mathbf{k}-\mathbf{P t}$ & 30 & 0.058 & & & & & & & \\
\hline k-Clay & $8.64 \times 10^{-4}$ & 0.055 & & & & & & & \\
\hline$k-L 2$ & $8.64 \times 10^{-2}$ & 0.036 & & & & & & & \\
\hline $\mathbf{k}-\mathbf{P i}$ & 30 & 0.024 & & & & & & & \\
\hline S - BLT_dx & $1 \times 10^{-4}$ & 0.017 & & & & & & & \\
\hline k-BLT_dx & 20 & 0.013 & & & & & & & \\
\hline S - F2 & $1 \times 10^{-4}$ & 0.013 & & & & & & & \\
\hline S-F1 & $1 \times 10^{-4}$ & 0.007 & & & & & & & \\
\hline$S-B C$ & $1 \times 10^{-4}$ & 0.004 & & & & & & & \\
\hline k - L1 & $8.64 \times 10^{-2}$ & 0.002 & & & & & & & \\
\hline k - F2 & 100 & 0.001 & & & & & & & \\
\hline k - F1 & 100 & 0.001 & & & & & & & \\
\hline S-Carb & $1 \times 10^{-7}$ & 0.001 & & & & & & & \\
\hline
\end{tabular}

Fig. 8 Model parameters ranked according to their sensitivity. The red bars indicate the parameters included in every MOD1 version, " $k$ " prefix indicates the hydraulic conductivity and "S" prefix indicates the specific storage

\section{Discussion}

The double recharge of the Riardo Plain aquifer, hypothesised according to the groundwater budget calculations (Viaroli

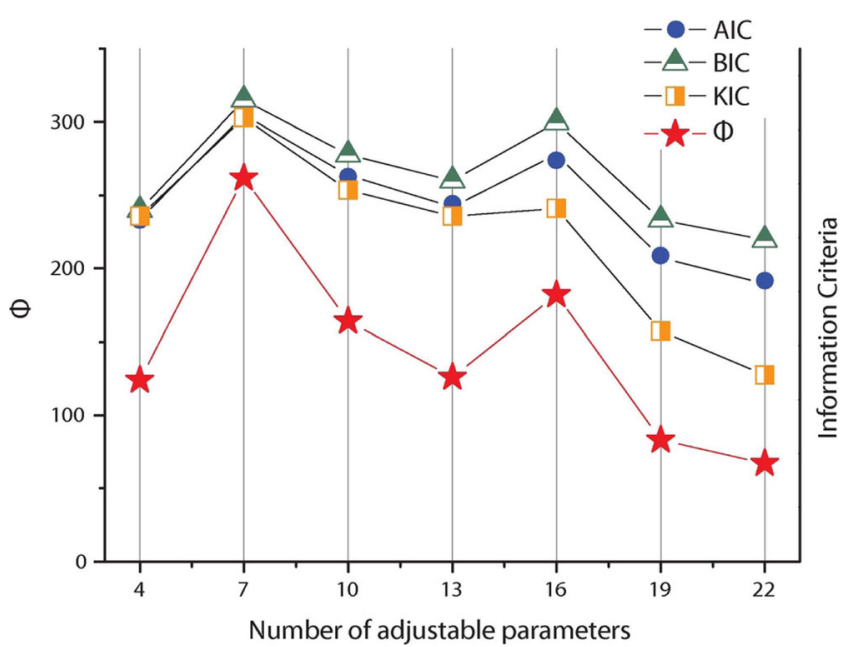

Fig. 9 Information criteria (AIC, BIC and KIC) and the sum of squared weighted residuals $(\Phi)$ calculated on the validated version of MOD1
Table 2 Values of the calibrated parameters in the optimal version of the MOD1

\begin{tabular}{lll}
\hline Zone & Hydraulic conductivity $(\mathrm{m} / \mathrm{d})$ & Specific storage \\
\hline L1 zone & 0.11 & $1.2 \times 10^{-4}$ \\
L2 zone & 0.015 & $7 \times 10^{-5}$ \\
Pt zone & 48 & $5 \times 10^{-4}$ \\
BLT zone & 0.09 & $2.5 \times 10^{-5}$ \\
Pi zone & 5 & $5.7 \times 10^{-5}$ \\
Clay zone & $1.9 \times 10^{-5}$ & $2.6 \times 10^{-5}$ \\
Carb zone & 90 & $1 \times 10^{-7}$ \\
F1 zone & 186 & $6.6 \times 10^{-5}$ \\
F2 zone & 200 & $4.6 \times 10^{-5}$ \\
BLT_dx zone & 50 & $4 \times 10^{-5}$ \\
BC zone & 0.01 & $8.7 \times 10^{-5}$ \\
\hline
\end{tabular}

et al. 2018), was tested using a 2D model in an attempt to constrain the possible ranges of inflows in the studied system. The contribution of an external deep inflow through the carbonate basement was preliminarily assumed equal to the calculated groundwater deficit (around $40 \%$ of the zenithal recharge). The Neumann BC, applied to the first model scenario (MOD1), simulated the deep contribution suggested in the conceptual model. The results of the MOD1 calibration and validation are coherent with the proposed conceptual model, based on a long-term groundwater budget calculation. Besides the quantitative results of the budget, another aspect was inspected. The tested hypothesis was that the wavelength and frequency of head oscillations are only a function of the volcanic aquifer behaviour (which includes infiltration and withdrawals), excluding any presence of a detectable modulation (or trend) provided by the deep inflow. At the same time, it was assumed that the absolute average head value ( $\mathrm{m}$ a.s.l.) was given by the combination of the two inflows.

The statistics on the residuals highlighted a small mean error and a good efficiency index, both for the volcanic and the carbonate portion of the aquifer (Table 3). The a priori assignation of the deep inflow value can give rise to uncertainty due to the lack of an experimental measurement or to the intrinsic uncertainties related to the methods of the estimation of the groundwater budget terms. In the last phase of this work, eight additional model scenarios with different deep inflow rates were calibrated and validated (Table 5). Values of the inflow rates were assigned on the basis of the conceptual model, considering the reliable ranges in agreement with the water budget. The zenithal recharge time series was kept the same in all model versions.

The calibrations of the eight model scenarios reached acceptable results in term of residuals, but in some cases the values of the estimated parameters deviated from the reliable ranges. The MOD2 version, for example, reproduces a model 


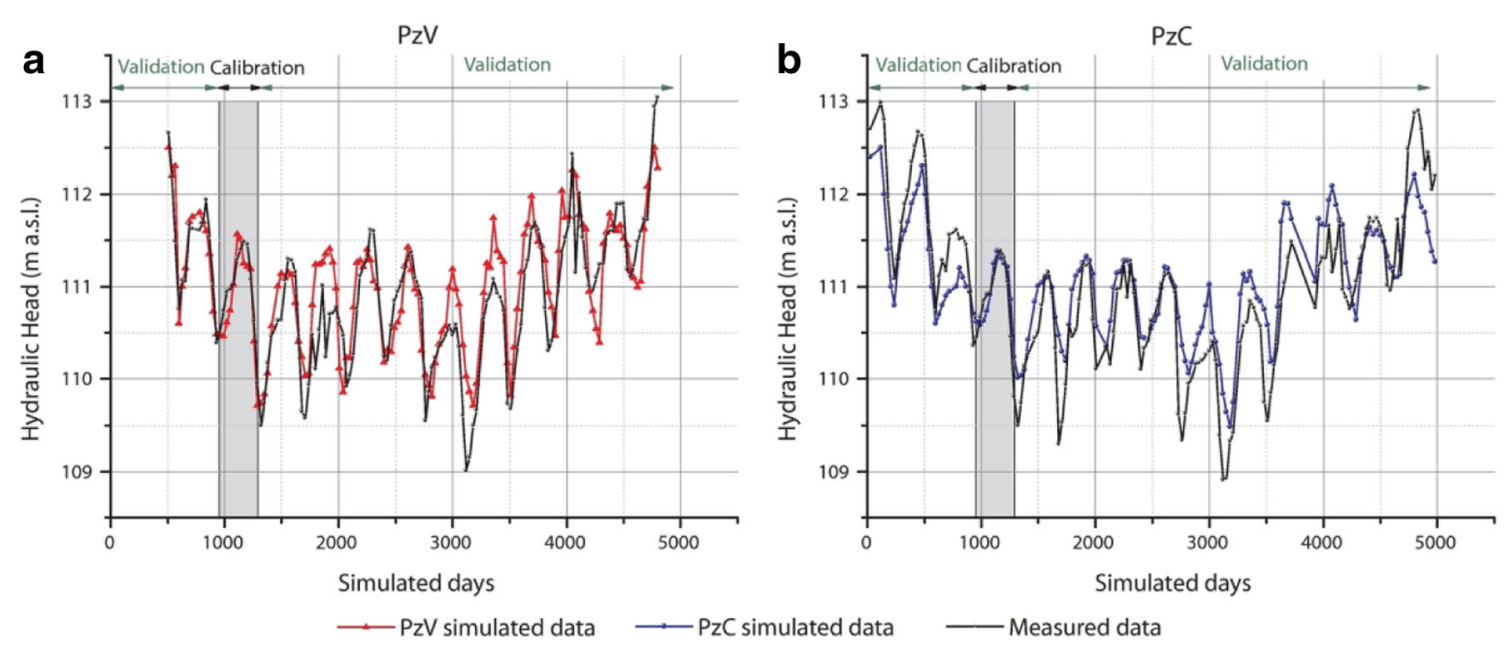

Fig. 10 Simulated hydraulic head values in $\mathbf{a} \mathrm{PzV}$ and $\mathbf{b} \mathrm{PzC}$ monitoring wells in the more efficient version of the MOD1

scenario where the recharge contribution derives only from the direct infiltration. This example was introduced simply as an extreme scenario, which has no relationship with the hydrogeological and geochemical data available in the literature (Capelli et al. 1999; Cuoco et al. 2010); therefore, the MOD2 version was neglected despite the acceptable numerical results.

On the opposite extreme, the MOD9 version is characterised by the highest simulated deep inflow (Table 5). The high amount of recharge forced the calibration to move the hydraulic parameters to reach their upper bounds imposed by the assigned ranges. This undesirable condition also reflects the scarce efficiency of the simulation $(\mathrm{NSE}=0.15$; Table 6).

The other model scenarios were characterised by a progressive increase of deep inflow; the statistical results are shown in Fig. 12. The MOD3, MOD4 and MOD5 versions showed an increase of model efficiency up to 0.68 and a decreasing RMSE to 0.45 . The MOD6-9 version presents a progressive increase of deep inflow and is characterised by the increase of the model error and a quick decrease in model efficiency. According to the results reported in Fig. 12, it is possible to define the most efficient model scenario (MOD5) corresponding to a deep inflow of around 34\% of the total recharge (direct infiltration + deep inflow). The MOD4 and MOD1 versions could also be considered acceptable model scenarios with a percentage of deep inflow ranging between 30 and 38\%.

Table 3 Statistics on residuals of the optimised version of MOD1

\begin{tabular}{llllll}
\hline Dataset & RMSE & R & NSE & RSR & NBI \\
\hline Complete dataset & 0.51 & 0.77 & 0.60 & 0.64 & 0.001 \\
Well PzV & 0.51 & 0.79 & 0.52 & 0.72 & 0.0 \\
Well PzC & 0.5 & 0.78 & 0.66 & 0.59 & 0.0006 \\
\hline
\end{tabular}

The post-calibration covariance matrix (recorded when manual regularisation is applied) reports variances and covariances of parameter error (given by the difference between estimated and expected value of parameters). The aim is to obtain variances and covariances as small as possible, reducing uncertainty with respect to the precalibration parameter uncertainty.

Results of MOD5 (calibrated according to 16 adjustable parameters) are reported in the electronic supplemental material (ESM). In general, the covariance matrix values are quite low, even if a few parameters are affected by a high covariance, and the specific storage of the BLT_dx zone (S - blt_dx in the ESM) presents an extremely high variance. This probably means that the calibration dataset contains a low amount of information able to reduce the uncertainty of that parameter.

The correlation matrix shows a wide range of positive and negative correlation values between the parameters involved in the calibration. Sometimes the values are close to the autocorrelation (Hill and Tiedeman 2007); therefore, a deep analysis of the eigenvectors and the eigenvalues (all tables in ESM) is necessary as suggested by Doherty (2015).

Table 4 Groundwater budget simulated over the 2000-2014 period (around 5000 days)

\begin{tabular}{lll}
\hline Water budget feature & Inflow $\left(\mathrm{m}^{3}\right)$ & Outflow $\left(\mathrm{m}^{3}\right)$ \\
\hline Neumann BC (total recharge) & 8,573 & 0 \\
Direct recharge & 5,328 & - \\
Deep inflow & 3,245 & - \\
Dirichlet BC & 0 & 3,739 \\
Well BC & 0 & 5,184 \\
Storage & Release: 6,680 & Capture: 6,330 \\
Total & 15,253 & 15,253 \\
\hline
\end{tabular}

The direct recharge and the deep inflow were quantified as portions of the total recharge using the zonal budget tool. $B C$ boundary condition. 
Table 5 Value assigned to each cell simulating the deep inflow (fluid flux BC)

\begin{tabular}{llr}
\hline Model scenario & Fluid flux BC $(\mathrm{m} / \mathrm{d})$ & $\Delta$ Inflow \\
\hline MOD2 & 0 & $-100 \%$ \\
MOD3 & -0.00016 & $-60 \%$ \\
MOD4 & -0.00028 & $-30 \%$ \\
MOD5 & -0.00034 & $-15 \%$ \\
MOD1 & -0.0004 & 0 \\
MOD6 & -0.00046 & $+15 \%$ \\
MOD7 & -0.00052 & $+30 \%$ \\
MOD8 & -0.00064 & $+60 \%$ \\
MOD9 & -0.004 & $+1000 \%$ \\
\hline
\end{tabular}

The eigenvalues of the 16 eigenvectors of the parameter covariance matrix range between $1.04 \times 10^{-4}$ and 2426 . The ratio of the highest to lowest eigenvalue of the post- calibration parameter error covariance matrix is $2.33 \times 10^{-7}$, which turns out to be lower than $5 \times 10^{7}$, allowing one to say that the numerical integrity of the inversion process is sufficiently good according to Doherty (2015). Refinement of the manual regularisation strategy could have lowered the ratio value, but the present configuration seemed to represent an acceptable compromise.

All MOD versions reveal a similar information content regarding the deep groundwater inflow. The absence of a significant bias of the simulated data over 15 years confirms the constant or quasi-constant rate of the inflow as already supposed in the hydrogeological conceptual model. Limited changes in inflow rates cannot nevertheless be excluded, nor possible changes over a much longer period with respect to the simulated one.

The most likely deep inflow rate, as suggested by the presented modelling process, is $34 \% \pm 4 \%$ of the total recharge. This qualitative range, applied to the quantitative groundwater budget calculations of the Riardo Plain aquifer reported in

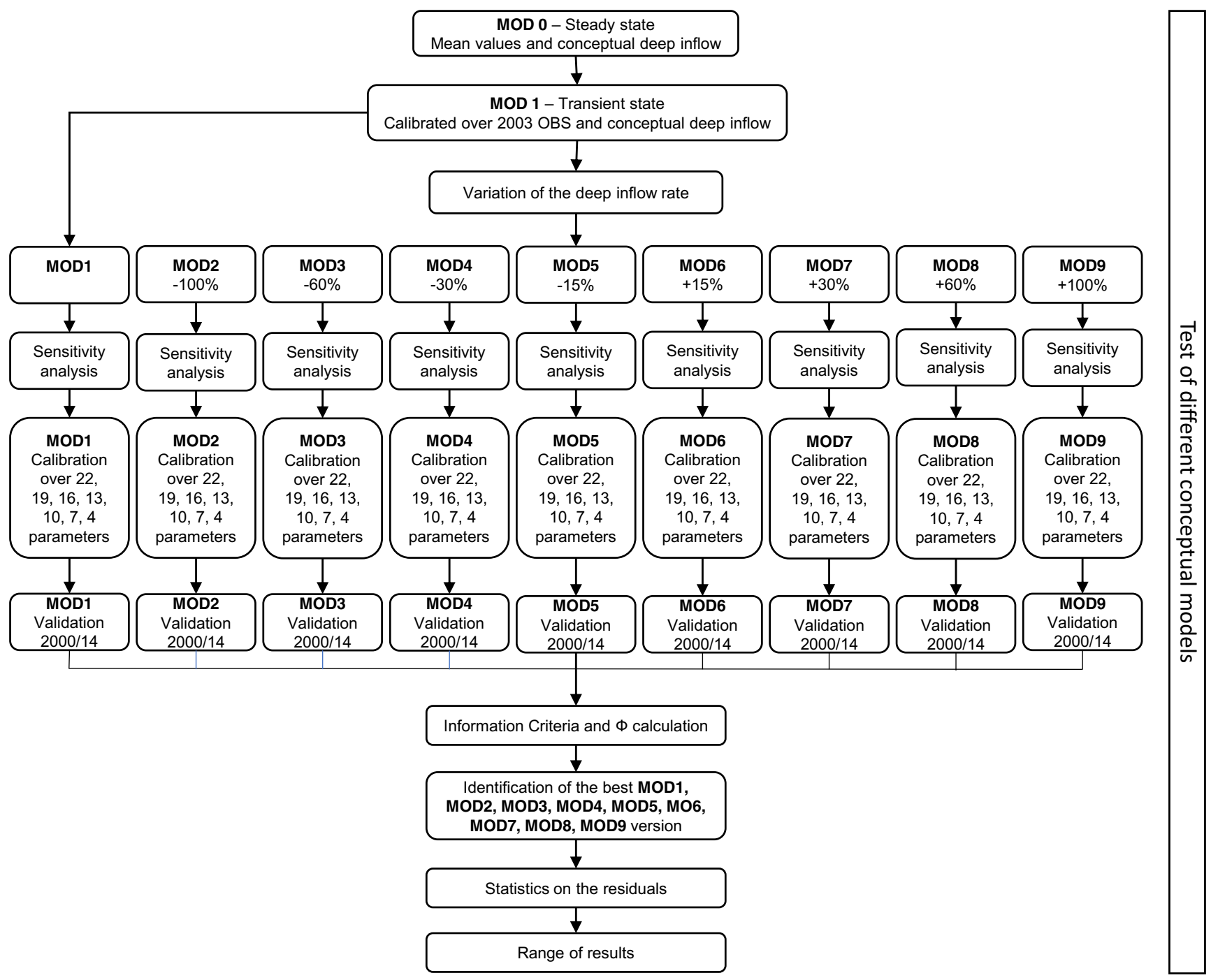

Fig. 11 Flowchart describing the activities of the second phase of the model elaboration 
Table 6 Statistics on the residuals of the best simulation of each model version

\begin{tabular}{lllllll}
\hline Model scenario & No. of adjustable parameters & RMSE & $R$ & NSE & RSR & NBI \\
\hline MOD2 & 19 & 0.55 & 0.8 & 0.52 & 0.70 & 0.001 \\
MOD3 & 19 & 0.60 & 0.73 & 0.45 & 0.75 & 0.001 \\
MOD4 & 16 & 0.49 & 0.75 & 0.63 & 0.62 & 0.001 \\
MOD5 & 16 & 0.45 & 0.84 & 0.69 & 0.57 & 0.000 \\
MOD1 & 22 & 0.51 & 0.77 & 0.60 & 0.64 & 0.001 \\
MOD6 & 16 & 0.57 & 0.7 & 0.49 & 0.72 & 0.001 \\
MOD7 & 19 & 0.63 & 0.66 & 0.38 & 0.80 & 0.001 \\
MOD8 & 19 & 0.68 & 0.64 & 0.29 & 0.85 & 0.002 \\
MOD9 & 10 & 0.73 & 0.4 & 0.17 & 0.92 & 0.000 \\
\hline
\end{tabular}

Table 7 Total and deep inflow calculated over the nine model scenarios in the 2000-2014 simulation period (around 5,000 days)
Fig. 12 Statistical indexes and percentage of deep inflow calculated for the model scenarios

\begin{tabular}{llccc}
\hline Model scenario & Neumann BC $(\mathrm{m} / \mathrm{d})$ & Total inflow $\left(\mathrm{m}^{3}\right)$ & Deep inflow $\left(\mathrm{m}^{3}\right)$ & Deep inflow $(\%)$ \\
\hline MOD2 & 0 & 5,328 & 0 & 0 \\
MOD3 & -0.00016 & 6,617 & 1,289 & 19 \\
MOD4 & -0.00028 & 7,584 & 2,256 & 30 \\
MOD5 & -0.00034 & 8,068 & 2,740 & 34 \\
MOD1 & -0.0004 & 8,573 & 3,245 & 38 \\
MOD6 & -0.00046 & 9,035 & 3,707 & 41 \\
MOD7 & -0.00052 & 9,518 & 4,190 & 44 \\
MOD8 & -0.00064 & 10,486 & 5,158 & 49 \\
MOD9 & -0.004 & 37,566 & 32,238 & 86 \\
\hline
\end{tabular}

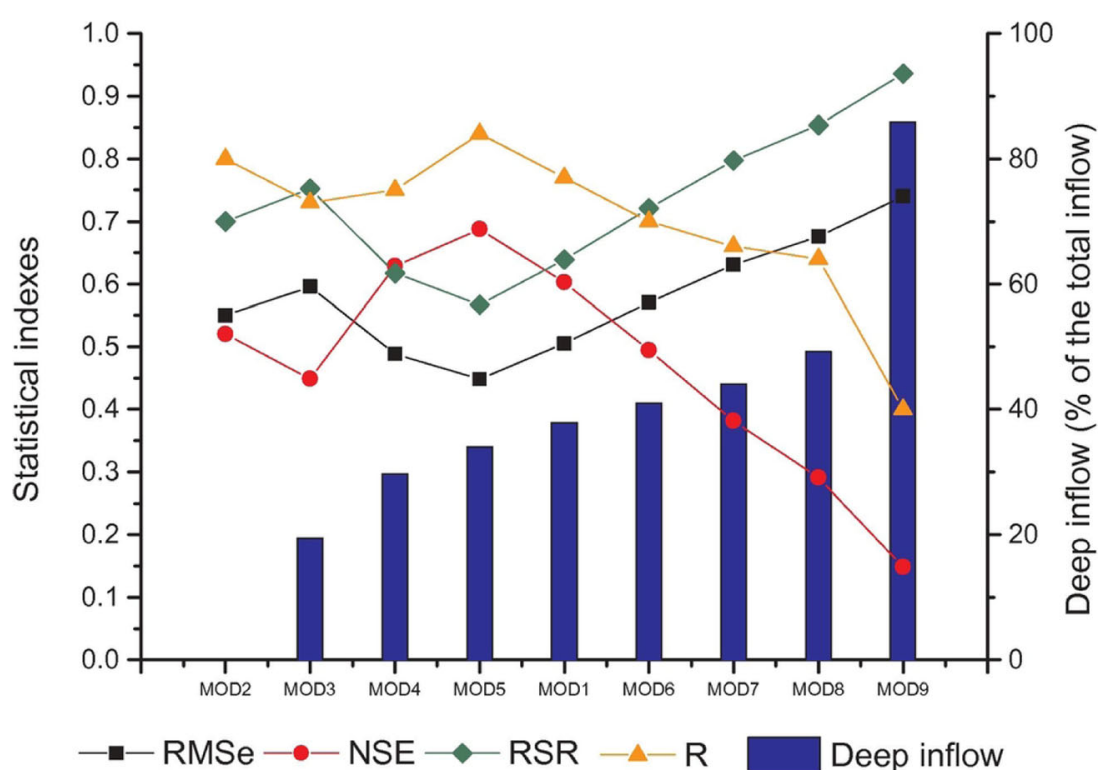


Viaroli et al. (2018), reveals an estimated inflow of around $415 \mathrm{~L} / \mathrm{s} \pm 50 \mathrm{~L} / \mathrm{s}$. This amount is in agreement with the hypothesis based only on the analytical groundwater budget calculations. The output variability revealed by the different model scenarios seems to be close to the order of magnitude of the intrinsic and ineliminable errors of the groundwater budget.

\section{Conclusions}

The knowledge of the dynamics of an aquifer could be increased using numerical models. This feature is extremely useful when vertical or lateral groundwater exchanges occur without the possibility of direct in-field measurements. The presence of external groundwater exchanges could sometimes be supposed only by means of the results of groundwater budget calculations, like in the Riardo Plain aquifer. Geochemical and isotopic data, in fact, are often not able to provide a unique hypothesis on the groundwater circulation in such complex systems. Different conceptual models must be supported by the most widespread number of analyses (hydrogeological, geochemical, etc.) and then tested via numerical simulations.

The implementation of a 3D numerical model at catchment scale could be a significant support for stakeholders and decision makers dealing with aqueducts, mineral water bottling activities and irrigation consortia for sustainable groundwater management. The presence of an additional source of recharge is surely a precious resource, but unfortunately it increases the uncertainties of any model attempt due to the absence of reliable information on the spatial distribution and inflow rate. For this reason, before creating the regional 3D model, the implementation of the small 2D model supported by a well-known geology and long-term hydraulic head observations, was the first step of the modelling process aimed at providing constraints for the next 3D model phase.

A 2D numerical model of the mixing area in the Riardo Plain was implemented in this study firstly to validate the conceptual model based on the result of the groundwater budget calculation. The simplified 2D model structure allowed the limitation of the unknowns affecting the simulated system, focusing only on the quantification of the inflow percentage through the carbonate basement. Seven versions of the model with an increasing number of adjustable parameters, ranked according to their sensitivities, were calibrated on the hydraulic head observations recorded in 2003 and were then validated over 15 years of monitoring. The comparison of the seven calibrated versions allowed one to identify the more efficient model version using the information criteria in order to further reduce the ranges of results. Once the conceptual model was validated, another eight model scenarios were implemented testing different inflow rates, using the same procedure previously described. The statistical results of the most efficient version of each model scenario allowed one to define a reliable range of inflow rate as $34 \% \pm 4 \%$ of the total recharge, if the presently available conceptual model is considered valid. This qualitative range, if applied to the quantitative groundwater budget calculations of the Riardo Plain aquifer, reveals an estimated inflow of around $415 \mathrm{~L} / \mathrm{s} \pm 50 \mathrm{~L} / \mathrm{s}$.

The percentages of inflow tested through this method will be used as starting conditions in the following $3 \mathrm{D}$ modelling at catchment scale, reducing the prior uncertainties of the hydrogeological system and limiting the possible solutions compared to a priori inflow value. The described procedure could easily be applied to similar hydrogeological contexts, helping the step by step understanding of the dynamics of complex aquifers in order to produce more reliable 3D numerical models.

Acknowledgements The authors thank the Kataclima team for their support during the modelling sessions. The authors also thank the editor Prof J.M. Lemieux, the associate editor Prof G. Porta, the anonymous reviewer, and Dott. M. Lancia for their helpful suggestions for improving the quality of the manuscript. This work was supported by Ferrarelle S.p.A. funding to the research project of the Roma Tre University on the Roccamonfina Volcano aquifer (research supervisor: Prof. Roberto Mazza).

Open Access This article is distributed under the terms of the Creative Commons Attribution 4.0 International License (http:// creativecommons.org/licenses/by/4.0/), which permits unrestricted use, distribution, and reproduction in any medium, provided you give appropriate credit to the original author(s) and the source, provide a link to the Creative Commons license, and indicate if changes were made.

\section{References}

Abdelaziz R, Merkel BJ (2012) Analytical and numerical modeling of flow in a fractured gneiss aquifer. J Water Resour Protect 4:657-662. https://doi.org/10.4236/jwarp.2012.48076

Adamowski J, Chan HF (2011) A wavelet neural network conjunction model for groundwater level forecasting. J Hydrol 407(1-4):28-40. https://doi.org/10.1016/j.jhydrol.2011.06.013

Akaike H (1973). Information theory as an extension of the maximum likelihood principle. In: Petrov BN, Csaki F (eds) Second international symposium on information theory. Akademiai Kiado, Budapest, pp 267-281

Alberti L, Colombo L, Formentin G (2018) Null-space Monte Carlo particle tracking to assess groundwater PCE (Tetrachloroethene) diffuse pollution in north-eastern Milan functional urban area. Sci Total Environ 621:326-339. https://doi.org/10.1016/j.scitotenv. 2017.11.253

Anderson MP, Woessner WW, Hunt RJ (2015) Applied groundwater modeling: simulation of flow and advective transport. Academic, San Diego, 630 pp

Andrés C, Ordóñez A, Álvarez R (2017) Hydraulic and thermal modelling of an underground mining reservoir. Mine Water Environ 36: 24-33. https://doi.org/10.1007/s10230-015-0365-1

Baiocchi A, Lotti F, Piscopo V (2013) Impact of groundwater withdrawals on the interaction of multi-layered aquifers in the Viterbo 
geothermal area (central Italy). Hydrogeol J 21(6):1339-1353. https://doi.org/10.1007/s10040-013-1000-5

Ballini A, Barberi F, Laurenzi MA, Mezzetti F, Villa IM (1989) Nuovi dati sulla stratigrafia del Vulcano di Roccamonfina [New data on the stratigraphy of the volcano of Roccamonfina]. Boll Gruppo Nazionale Vulcanolog 5(2):533-555

Boncio P, Dichiarante AM, Auciello E, Saroli M, Stoppa F (2016) Normal faulting along the western side of the Matese Mountains: implications for active tectonics in the central Apennines (Italy). J Struct Geol 82:16-36. https://doi.org/10.1016/j.jsg.2015.10.005

Boni C, Bono P, Capelli G (1986) Schema idrogeologico dell'Italia Centrale [Hydrogeological scheme of the central Italy]. Mem Soc Geol It 35(2):991-1012

Bredehoeft J (2005) The conceptualization model problem: surprise. Hydrogeol J 13(1):37-46. https://doi.org/10.1007/s10040-004$0430-5$

Capelli G, Mazza R, Trigari A, Catalani F (1999) Le risorse idriche sotterranee strategiche nel distretto vulcanico di Roccamonfina (Campania Nord-occidentale) [Strategic groundwater resources in the Roccamonfina volcanic district (north-west Campana region)]. Quad Geolog Appl 4:23-32

Capuano P, Continisio R, Gasparini P (1992) Structural setting of a typical alkali-potassic volcano: Roccamonfina, southern Italy. J Volcanol Geotherm Res 53(1-4):355-369. https://doi.org/10.1016/ 0377-0273(92)90091-Q

Carrera J, Neuman SP (1986a) Estimation of aquifer parameters under transient and steady-state conditions: 1 . maximum likelihood method incorporating prior information. Water Resour Res 22(2):199210. https://doi.org/10.1029/WR022i002p00199

Carrera J, Neuman SP (1986b) Estimation of aquifer parameters under transient and steady-state conditions: 2. uniqueness, stability, and solution algorithms. Water Resour Res 22(2):211-227. https://doi. org/10.1029/WR022i002p00211

Carrera J, Neuman SP (1986c) Estimation of aquifer parameters under transient and steady-state conditions: 3 . application to synthetic and field data. Water Resour Res 22(2):228-242. https://doi.org/10. 1029/WR022i002p00228

Celico P (1983) Idrogeologia dell'Italia Centro-Meridionale [Hydrogeology of the central and southern Italy)]. Quad Cass Mezz 4(2)

Cosentino D, Federici I, Cipollari P, Gliozzi E (2006) Environments and tectonic instability in Central Italy (Garigliano basin) during the late Messinian Lago-Mare episode: new data from the onshore Mondragone 1 well. Sediment Geol 188-189:297-317. https://doi. org/10.1016/j.sedgeo.2006.03.010

Cuoco E, Darrah TH, Buono G, Verreggia G, De Francesco S, Eymold WK, Tedesco D (2015) Inorganic contaminants from diffuse pollution in shallow groundwater of the Campanian plain (southern Italy): implications for geochemical survey. Environ Monit Assess 187(46). https://doi.org/10.1007/s10661-015-4307-y

Cuoco E, Verrengia G, De Francesco S, Tedesco D (2010) Hydrogeochemistry of Roccamonfina volcano (southern Italy). Environ Earth Sci 61(3):525-538. https://doi.org/10.1007/s12665009-0363-3

D’Argenio B, Pescatore T (1962) Stratigrafia del Mesozoico nel gruppo del Monte Maggiore (Caserta) [Stratigraphy of the Mesozoic units of the Mount Maggiore (Caserta)]. Boll Soc Naturalist Napoli 71: $55-61$

De Vivo B, Rolandi G, Gans PB, Calvert A, Bohrson WA, Spera FJ, Belkin HE (2001) New constraints on the pyroclastic eruptive history of the Campanian volcanic plain (Italy). Miner Petrol 73(1-3): 47-65, doi:https://doi.org/10.1007/s007100170010

Doherty J (2010) PEST, model-independent parameter estimation manual. Watermark, Brisbane, Australia, $279 \mathrm{pp}$

Doherty J (2012) Addendum to the PEST manual. Watermark, Brisbane, Australia
Doherty J (2015) Calibration and uncertainty analysis for complex environmental models. Watermark, Brisbane, Australia, $227 \mathrm{pp}$

Engelhardt I, De Aguinaga JG, Mikat H, Schüth C, Liedl R (2014) Complexity vs. simplicity: groundwater model ranking using information criteria. Groundwater 52(4):573-583. doi:https://doi.org/10. 1111/gwat.12080

Foglia L, Mehl SW, Hill MC, Perona P, Burlando P (2007) Testing alternative ground water models using cross-validation and other methods. Groundwater 45(5):627-641. https://doi.org/10.1111/j. 1745-6584.2007.00341.x

Giacopetti M, Crestaz E, Materazzi M, Pambianchi G, Posavec K (2016) A multi-model approach using statistical index and information criteria to evaluate adequacy of the model geometry in a fissured carbonate aquifer (Italy). Water 8(7):271. https://doi.org/10.3390/ w8070271

Giordano G, Naso G, Scrocca D, Funiciello R, Catalani F (1995) Processi di estensione e circolazione di fluidi a bassa termalità nella Piana di Riardo (Caserta, Appennino centro-meridionale) [Extensional processes and low thermal fluid circulation in the Riardo Plain (Caserta, central-southern Apennine)]. Boll Soc Geol Ital 144:361-371

Golmohammadi G, Prasher S, Madani A, Rudra R (2014) Evaluating three hydrological distributed watershed models: MIKE-SHE, APEX, SWAT. Hydrology 1(1):20-39. https://doi.org/10.3390/ hydrology 1010020

Hemker K, Post V (2010) MLU for Windows 2.25: user's guide. SCRIBD, 30 pp. https://www.scribd.com. Accessed December 2018

Hemker CJ, Maas C (1987) Unsteady flow to wells in layered and fissured aquifer systems. J Hydrol 90(3-4):231-249. https://doi.org/ 10.1016/0022-1694(87)90069-2

Herckenrath D, Langevin CD, Doherty J (2011) Predictive uncertainty analysis of a saltwater intrusion model using null-space Monte Carlo. Water Resour Res 47:W05504. https://doi.org/10.1029/ 2010WR009342

Hill MC (2006) The practical use of simplicity in developing ground water models. Groundwater 44(6):775-781. https://doi.org/10. $1111 / \mathrm{j} .1745-6584.2006 .00227 . x$

Hill MC, Tiedeman CR (2007) Effective groundwater model calibration with analysis of data, sensitivities, predictions, and uncertainty. Wiley, Hoboken, NJ, 455 pp

Kashyap RL (1982) Optimal choice of AR and MA parts in autoregressive moving average models. IEEE Trans Pattern Anal Mach Intell 4(2):99-104. https://doi.org/10.1109/TPAMI.1982. 4767213

Lancia M, Saroli M, Petitta M (2018) A double scale methodology to investigate flow in karst fractured media via numerical analysis: the Cassino plain case study (central Apennine, Italy). Geofluids 2018: 2937105, pp 1-12. https://doi.org/10.1155/2018/2937105

Locardi E (1988) The origin of the Apenninic arcs. In: Wezel FC (ed) The origin and evolution of arcs. Tectonophysics 146:105-123. https:// doi.org/10.1016/0040-1951(88)90085-6

Luhr JF, Giannetti B (1987) The Brown Leucitic tuff of Roccamonfina volcano (Roman region, Italy). Contrib Mineral Petrol 95(4):420 436. https://doi.org/10.1007/BF00402203

Maréchal JC, Dewandel B, Ahmed S, Galeazzi L, Zaidi FK (2006) Combined estimation of specific yield and natural recharge in a semi-arid groundwater basin with irrigated agriculture. J Hydrol 329(1-2):281-293. https://doi.org/10.1016/j.jhydrol.2006.02.022

Maréchal JC, Lachassagne P, Ladouche B, Dewandel B, Lanini S, Le Strat P, Petelet-Giraud E (2013) Structure and hydrogeochemical functioning of a sparkling natural mineral water system determined using a multidisciplinary approach: a case study from southern France. Hydrogeol J 22(1):47-68. https://doi.org/10.1007/s10040013-1073-1

Massmann C, Birk S, Liedl R, Geyer T (2006) Identification of hydrogeological models: application to tracer test analysis in a karst aquifer, calibration and reliability in groundwater modelling: from 
uncertainty to decision making. IAHS Publ 304, IAHS, Wallingford, UK, pp 59-64

Matiatos I, Varouchakis EA, Papadopoulou MP (2014) Statistical sensitivity analysis of multiple groundwater mass transport models. Proceedings of 10th International Hydrogeological Congress of Greece, Thessaloniki, October 2010, pp 447-456

Nash JE, Sutcliffe JV (1970) River flow forecasting through conceptual models part I: a discussion of principles. J Hydrol 10(3):282-290. https://doi.org/10.1016/0022-1694(70)90255-6

Nunziata C, Gerecitano F (2012) $V_{s}$ crustal models of the Roccamonfina volcano and relationship with Neapolitan volcanoes (southern Italy). Int J Earth Sci 101:1371-1383. https://doi.org/10.1007/s00531-0110722-7

Peccerillo A (2005) Plio-Quaternary volcanism in Italy. Springer, Berlin, $321 \mathrm{pp}$

Poeter EP, Anderson D (2005) Multimodel ranking and interference in ground water modeling. Ground Water 43(4):597-605. https://doi. org/10.1111/j.1745-6584.2005.0061.x

Pola M, Fabbri P, Piccinini L, Zampieri D (2015) Conceptual and numerical models of a tectonically-controlled geothermal system: a case study of the Euganean geothermal system, northern Italy. Cent Eur Geol 58(1-2):129-151. https://doi.org/10.1556/24.58.2015.1-2.9

Renz A, Rühaak W, Schätzl P, Diersch HJG (2009) Numerical modeling of geothermal use of mine water: challenges and examples. Mine Water Environ 28:2-14. https://doi.org/10.1007/s10230-008-0063-

Rouchon V, Gillot PY, Quidelleur X, Chiesa S, Floris B (2008) Temporal evolution of the Roccamonfina volcanic complex (Pleistocene), central Italy. J Volcanol Geotherm Res 177:500-514. https://doi.org/10. 1016/j.jvolgeores.2008.07.016

Sahoo S, Jha MK (2017) Numerical groundwater-flow modeling to evaluate potential effects of pumping and recharge: implications for sustainable groundwater management in the Mahanadi Delta region, India. Hydrogeol J 25(8):2489-2511. https://doi.org/10.1007/ s10040-017-1610-4

Saroli M, Lancia M, Albano M, Mondoni G, Moro M, Scarascia Mugnozza G (2014) New geological data on the Cassino intramontane basin, central Apennines, Italy. Rendiconti Lincei 25(2):189-196. https://doi.org/10.1007/s12210-014-0338-5

Saroli M, Lancia M, Albano M, Casale A, Giovinco G, Petitta M, Zarlenga F, Dell'Isola M (2017) A hydrogeological conceptual model of the Suio hydrothermal area (central Italy). Hydrogeol J 25(6): 1811-1832. https://doi.org/10.1007/s10040-017-1549-5

Schwarz G (1978) Estimating the dimension of a model. Ann Stat 6(2): 461-464

Sena C, Molinero J (2009) Water resources assessment and hydrogeological modelling as a tool for the feasibility study of a closure plan for an open pit mine (La Respina mine, Spain). Mine Water Environ 28:94-101. https://doi.org/10.1007/s10230-009-0067-7
Sepúlveda N, Doherty J (2015) Uncertainty analysis of a groundwater flow model in east-central Florida. Groundwater 53(3):464-474. https://doi.org/10.1111/gwat.12232

Singh A (2014) Groundwater resources management through the applications of simulation modeling: a review. Sci Total Environ 499: 414-423. https://doi.org/10.1016/j.scitotenv.2014.05.048

Singh A, Mishra S, Ruskauff R (2010) Model averaging techniques for quantifying conceptual model uncertainty. Groundwater 48(5):701715. https://doi.org/10.1111/j.1745-6584.2009.00642.x

Thornthwaite CW, Mather JR (1955) The water balance. Climatology $8(1): 104$

Tichy M (1993) Applied methods of structural reliability. Springer, Dordrecht, $403 \mathrm{pp}$

Tonkin M, Doherty J (2009) Calibration-constrained Monte Carlo analysis of highly parametrized models using subspace techniques. Water Resour Res 45:W00B10. https://doi.org/10.1029/2007WR006678

Trefry MG, Muffels C (2007) FEFLOW: a finite-element groundwater flow and transport-modeling tool. Groundwater 45(5):525-528. https://doi.org/10.1111/j.1745-6584.2007.00358.x

Turco E, Schettino A, Pierantoni PP, Santarelli G (2006) Chapter 2 the Pleistocene extension of the Campania plain in the framework of the southern Tyrrhenian tectonic evolution: morphotectonic analysis, kinematic model and implications for volcanism. In: De Vivo B (ed) Volcanism in the Campania plain Vesuvius, Campi Flegrei and ignimbrites, vol 9. Elsevier, Amsterdam, pp 27-51

Viaroli S, Cuoco E, Mazza R, Tedesco D (2016a) Dynamics of natural contamination by aluminum and iron rich colloids in the volcanic aquifers of central Italy. Environ Sci Pollut Res 23:19958-19977. https://doi.org/10.1007/s11356-016-7198-8

Viaroli S, Mastrorillo L, Mazza R, Paolucci V (2016b) Hydrostructural setting of Riardo plain: effects on Ferrarelle mineral water type. Acque Sotterranee 5(3):59-68. https://doi.org/10.7343/as-2016-226

Viaroli S, Mastrorillo L, Lotti F, Paolucci V, Mazza R (2018) The groundwater budget: a tool for preliminary estimation of the hydraulic connection between neighboring aquifers. J Hydrol 556:72-86. https://doi.org/10.1016/j.jhydrol.2017.10.066

Watts MD (1987) Geothermal exploration of the Roccamonfina volcano, Italy. Geothermics 16(5-6):517-528

Ye M, Meyer PD, Neuman SP (2008) On model selection criteria in multimodel analysis. Water Resour Res 44(3):W03428. https://doi. org/10.1029/2008WR006803

Ye M, Pohlmann KF, Chapman JB, Pohll GM, Reeves DM (2010) A model-averaging method for assessing groundwater conceptual model uncertainty. Groundwater 48(5):716-728. https://doi.org/10. $1111 / j .1745-6584.2009 .00633 . x$

Zhou Y, Herath HMPSD (2017) Evaluation of alternative conceptual models for groundwater modelling. Geosci Front 8:437-443. https://doi.org/10.1016/j.gsf.2016.02.002 